\title{
On the reversible deactivation of cobalt ferrite spinel nanoparticles applied in selective 2-propanol oxidation
}

\author{
Sven Anke ${ }^{\mathrm{a}}$, Tobias Falk ${ }^{\mathrm{a}}$, Georg Bendt ${ }^{\mathrm{b}}$, Ilya Sinev ${ }^{\mathrm{c}}$, Michael Hävecker ${ }^{\mathrm{de}}$, Hendrik Antoni ${ }^{\mathrm{a}}$, \\ Ioannis Zegkinoglou ${ }^{\mathrm{c}}$, Hyosang Jeon ${ }^{\mathrm{f}}$, Axel Knop-Gericke ${ }^{\mathrm{d}}$, Robert Schlögl ${ }^{\mathrm{d}, \mathrm{e}}$, Beatriz Roldan \\ Cuenya $^{\mathrm{f}}$, Stephan Schulz ${ }^{\mathrm{b}}$, Martin Muhler ${ }^{\mathrm{a}, \mathrm{e} *}$ \\ ${ }^{a}$ Laboratory of Industrial Chemistry, Ruhr-University Bochum, 44780 Bochum, Germany. E- \\ mail:muhler@techem.rub.de \\ ${ }^{b}$ Faculty of Chemistry, Inorganic Chemistry, and Center for Nanointegration DuisburgEssen \\ (CENIDE), University of Duisburg-Essen, 45114 Essen, Germany \\ ${ }^{c}$ Department of Physics, Ruhr-University Bochum, 44780 Bochum, Germany \\ ${ }^{d}$ Department of Inorganic Chemistry Fritz-Haber Institute of the Max Planck Society, 14195 \\ Berlin, Germany \\ ${ }^{\mathrm{e}}$ Department of Heterogeneous Reactions, Max Planck Institute for Chemical Energy \\ Conversion, 45470 Mülheim an der Ruhr, Germany \\ ${ }^{\mathrm{f}}$ Department of Interface Science, Fritz-Haber Institute of the Max Planck Society, 14195 \\ Berlin, Germany \\ * Corresponding author. E-mail address: muhler@techem.rub.de (M. Muhler).
}

Keywords: Cobalt ferrite, Selective oxidation, Surface spectroscopy, 2-Propanol, Deactivation

\begin{abstract}
$\mathrm{CoFe}_{2} \mathrm{O}_{4}$ nanoparticles (NPs) were synthesized by using a colloidal one-pot synthesis method based on the decomposition of metal acetylacetonates in the presence of oleyl amine. The characterization by X-ray diffraction, transmission electron microscopy and $\mathrm{N}_{2}$ physisorption revealed non-porous spinel phase $\mathrm{CoFe}_{2} \mathrm{O}_{4}$ NPs with an average particle size of $4 \mathrm{~nm}$. The unsupported metal oxide NPs were applied in the selective oxidation of 2-propanol in a continuously operated fixed-bed reactor under quasi steady-state conditions using a heating rate of $0.5 \mathrm{k} \mathrm{min}^{-1}$. 2-Propanol was found to be oxidatively dehydrogenated over $\mathrm{CoFe}_{2} \mathrm{O}_{4}$ yielding acetone and $\mathrm{H}_{2} \mathrm{O}$ with high selectivity. Only to a minor extent dehydration to propene and total
\end{abstract}


oxidation to $\mathrm{CO}_{2}$ was observed at higher temperatures. The detected low-temperature reaction pathway with maxima at 430 and $510 \mathrm{~K}$ was inhibited after the initial 2-propanol oxidation up to $573 \mathrm{~K}$, but an oxidative treatment in $\mathrm{O}_{2}$ or $\mathrm{N}_{2} \mathrm{O}$ atmosphere led to full regeneration. No correlation between the desorbing amount or the surface oxygen species investigated by $\mathrm{O}_{2}$ temperature-programmed desorption experiments and the low-temperature activity was observed. The amounts of evolving $\mathrm{CO}_{2}$ during the TPO experiments indicate deactivation due to formation of carbonaceous species. Inhibition experiments with pre-adsorbed reaction intermediates and infrared spectroscopy identified acetate species as reversible poison, whereas carbonates are rather spectators. In addition, carbon deposition was detected by X-ray photoelectron spectroscopy, which also revealed a minor influence of cobalt reduction during the deactivation process as confirmed by X-ray absorption spectroscopy studies.

\section{Introduction}

Cobalt-based spinel nanoparticles (NPs) have the potential to replace commonly used oxidation catalysts containing noble metals, as they showed promising results in industrially relevant applications such as the oxidation of CO or volatile organic compounds (VOCs).[1,2] Due to the presence of octahedral and tetrahedral sites both in normal and inverse spinels, the catalyst composition can be varied over a broad range, while the spinel structure remains intact. Hence, the catalytic properties can be tuned by adding different metal cations - both divalent $\mathrm{M}^{2+}$ and trivalent $\mathrm{M}^{3+}$ ions - to the oxygen anion sublattice. In an inverse spinel structure like cobalt ferrite $\left(\mathrm{CoFe}_{2} \mathrm{O}_{4}\right)$ the divalent cations $\left(\mathrm{Co}^{2+}\right)$ occupy $1 / 4$ of the octahedral sites, while the trivalent cations $\left(\mathrm{Fe}^{3+}\right)$ occupy $1 / 8$ of the tetrahedral and $1 / 4$ of octahedral sites. $\mathrm{Gu}$ et al.[3] used different $\mathrm{Co}^{2+/ 3+}$-containing spinels to investigate the influence of the cobalt oxidation state as well as the coordination number of the cobalt cations in the spinel structure on the catalytic

performance in $\mathrm{CO}$ oxidation. Their results indicated that $\mathrm{Co}^{3+}$ in octahedral sites is the active site, while at higher temperatures nearly full $\mathrm{CO}$ conversion was achieved over the inverse 
spinel $\mathrm{CoFe}_{2} \mathrm{O}_{4}$, which contains only octahedrally coordinated $\mathrm{Co}^{2+}$ similar to CoO.[3] The catalytic activity is ascribed to the easily oxidized $\mathrm{Co}^{2+}$ cations in the octahedral sites-due to the higher ligand field stabilization of $\mathrm{Co}^{3+}$ as compared with $\mathrm{Co}^{2+}$ in an oxide environment. The coordination of the cobalt ions depends strongly on the composition of the spinel and the preparation method.[4] The strong influence of the synthesis route on the structural and catalytic properties in 2-propanol oxidation and the oxygen evolution reaction (OER) was recently demonstrated for $\mathrm{CoFe}_{2} \mathrm{O}_{4}$.[5] The positive effect of the partial substitution of Co by Fe cations was shown by Haruta and coworkers.[6] The Fe-doped $\mathrm{Co}_{3} \mathrm{O}_{4}$ catalysts revealed superior catalytic activity in $\mathrm{CO}$ oxidation in comparison to $\mathrm{Cr}$-doped $\mathrm{Co}_{3} \mathrm{O}_{4}$ or undoped $\mathrm{Co}_{3} \mathrm{O}_{4}$, with a shift of the $50 \%$ conversion temperature $\left(\mathrm{T}_{50}\right)$ from $273 \mathrm{~K}$ to $188 \mathrm{~K}$. The differences were correlated to changes in the $\mathrm{Co}^{3+}-\mathrm{O}^{2-}$ bonding, which is influenced by the redox properties of the metal dopants. Haruta and coworkers [6] additionally emphasized the application of metaldoped $\mathrm{Co}_{3} \mathrm{O}_{4}$ materials in selective oxidation processes due to the enhanced stability during oxidation reactions and the availability of reactive oxygen species at low temperatures, which was also observed in our previous study [7] for the interaction of 2-propanol with $\mathrm{Co}_{3} \mathrm{O}_{4}$ surfaces.

Usually mixed metal oxide catalysts exhibit higher resistance to poisoning and high thermal stability. Nevertheless, deactivation of $\mathrm{CoFe}_{2} \mathrm{O}_{4}$ or $\mathrm{Co}_{3} \mathrm{O}_{4}$ catalysts during oxidation reactions due to carbon deposition was reported.[8,9] Gaining insight regarding the deactivation phenomena is of crucial importance for the understanding of the reaction mechanism and the design of superior catalysts. Vozniuk et al.[8] observed the formation of coke and aromatics, over $\mathrm{CoFe}_{2} \mathrm{O}_{4}$ catalysts during anaerobic ethanol decomposition. They suggested that the deposited coke originates from the dehydrogenation and deoxygenation of ethanol as well as from the Boudouard reaction. In an earlier study, the same group performed the anaerobic ethanol decomposition reaction over Co-containing mixed ferrospinels and identified acetates and carbonates as important reaction intermediates by DRIFTS experiments.[10] For the 2propanol oxidation over $\mathrm{Co}_{3} \mathrm{O}_{4}$, Busca et al.[11] proposed mechanisms for the partial and total 
oxidation and identified a reaction sequence of adsorbed isopropoxide to gas-phase $\mathrm{CO}_{\mathrm{x}}$ via adsorbed acetone and acetates. The oxidized $\mathrm{Co}_{3} \mathrm{O}_{4}$ surface was described as a layer exclusively containing $\mathrm{Co}^{3+}$ species coupled with excess oxygen in the form of $\mathrm{O}^{2-}$ anions, [11] whereas also other di- or monoatomic oxygen species were reported.[12-14]

For the formation of reactive oxygen species on catalyst surfaces, nitrous oxide $\left(\mathrm{N}_{2} \mathrm{O}\right)$ is often used and its decomposition on spinel surfaces is quite well investigated due to its high global warming potential.[15,16] Sojka and co-workers[17] reported that the catalytic activity of $\mathrm{Co}_{3} \mathrm{O}_{4}$ in $\mathrm{N}_{2} \mathrm{O}$ decomposition originates from the $\mathrm{Co}^{3+} / \mathrm{Co}^{4+}$ redox couple, which operates along a reversible one-electron process, leading to the formation of $\mathrm{O}^{-}$surface oxygen intermediates.

Recently, we reported on the catalytic performance of unsupported $\mathrm{Co}_{3} \mathrm{O}_{4}$ NPs in selective 2-propanol oxidation.[7] For the highly active and selective catalyst two reaction pathways were observed depending on the reaction temperature. When raising the reaction temperature under quasi steady-state conditions up to $573 \mathrm{~K}$ a maximum in the yield of acetone was observed at $430 \mathrm{~K}$, followed by a second oxidation reaction at higher temperatures. The high-temperature reaction pathway remained stable, while the activity at lower temperatures was no longer detected in a subsequent oxidation run. However, the low-temperature activity can be regenerated by oxidative treatment at $573 \mathrm{~K}$ due to the removal of carbonaceous residues and the reoxidation of the catalyst surface. However, the nature of the adsorbed species remaining on the surface was not identified and it remained an open question whether catalyst reduction, consumption of reactive oxygen species, or site blocking by strongly bound adsorbates has the largest impact on deactivation of the low-temperature reaction pathway.

The goal of this study was to improve the understanding of the different reaction pathways occurring during selective 2-propanol oxidation over $\mathrm{CoFe}_{2} \mathrm{O}_{4}$. A combination of temperatureprogrammed (TPD, TPO) and in situ/operando spectroscopic methods (DRIFTS, X-ray photoelectron spectroscopy (XPS), and X-ray absorption spectroscopy (XAS)) as well as inhibition experiments was applied to examine the deactivation and regeneration process of 
$\mathrm{CoFe}_{2} \mathrm{O}_{4}$ to gain deeper insight into the mechanism of 2-propanol oxidation, addressing the influence of reaction intermediates, surface reduction and reactive surface oxygen species.

\section{Experimental}

\subsection{Catalysts synthesis}

A mixture of $10 \mathrm{mmol} \mathrm{Fe}(\mathrm{acac})_{3}$ and $5 \mathrm{mmol} \mathrm{Co}(\mathrm{acac})_{2}$ was suspended in $60 \mathrm{~mL}$ of oleylamine. The mixture was first heated to $373 \mathrm{~K}$ for 10 min to remove low boiling solvents, resulting in a clear red solution. The temperature was then raised to $523 \mathrm{~K}$ and kept constant for $60 \mathrm{~min}$. After the solution had cooled to ambient temperature, the $\mathrm{CoFe}_{2} \mathrm{O}_{4} \mathrm{NPs}$ were precipitated by adding $10 \mathrm{~mL}$ of ethanol. The precipitate was isolated by centrifugation, purified by repeated washing (2-3 times) with chloroform/ethanol (1:1) and dried in vacuum. The surfactant oleylamine was removed from the dried powders by calcination at $573 \mathrm{~K}$ for $3 \mathrm{~h}$ in air, and the absence of organic residues was shown by IR spectroscopy.

\subsection{Structural characterization}

XRD patterns were recorded using a Bruker D8 Advance powder diffractometer with $\mathrm{Cu}-$ $\mathrm{K} \alpha$ radiation $(\lambda=1.5418 \AA, 40 \mathrm{kV}$ and $40 \mathrm{~mA})$ using a silicon single crystal as sample holder for minimized scattering. The powders were redispersed in ethanol, deposited on the silicon surface and investigated in the $2 \theta$ range from 20 to $80^{\circ}$ with a step size of $0.01^{\circ}$ and a counting time of $0.6 \mathrm{~s}$.

Nitrogen physisorption measurements were performed at $77 \mathrm{~K}$ in a BELSORP-mini (BEL Japan, Inc.). $200 \mathrm{mg}$ of the sample using a sieve fraction of 250-355 $\mu \mathrm{m}$ were pretreated at 473 $\mathrm{K}$ for $2 \mathrm{~h}$ under vacuum to remove adsorbed water. The specific surface areas were derived from the adsorption isotherms using the BET method. Applying the BJH method, the pore volume and the pore size distribution were obtained.

XPS measurements were carried out in an ultra-high vacuum set-up (UHV) equipped with a high resolution Gammadata-Scienta SES 2002 analyzer. A monochromatic A1 K ${ }_{\alpha}$ X-ray source 
(1486.3 eV; anode operating at $14.5 \mathrm{keV}$ and $30.5 \mathrm{~mA}$ ) was used as incident radiation and a pass energy of $200 \mathrm{eV}$ was chosen resulting in an energy resolution better than $0.5 \mathrm{eV}$. Charging effects were compensated using a flood gun. Binding energies were calibrated by positioning the main $\mathrm{C} 1 \mathrm{~s}$ peak at $284.5 \mathrm{eV}$.

TEM images of the $\mathrm{CoFe}_{2} \mathrm{O}_{4}$ NPs were recorded with a JEOL 2010 microscope operated at $200 \mathrm{kV}$ acceleration voltage. SEM measurements were carried out in an FEI Quanta 4D FEG 600 equipped with a secondary electron detector operated at $30 \mathrm{keV}$.

XAS was measured at a wiggler beamline CLÆSS[18] of the ALBA synchrotron radiation facility (Barcelona, Spain). A Si(111) double crystal monochromator was used for the energy scan and detuned to $65 \%$ of its efficiency to reject higher harmonics. The spectra were recorded in transmission mode at room temperature and during 2-propanol dehydrogenation at fixed temperatures. For the measurements, $\mathrm{CoFe}_{2} \mathrm{O}_{4} \mathrm{NP}$ powder was pressed in a self-supporting pellet and mounted in an in situ cell provided by the CLÆSS beamline. A reference metallic foil was measured in each scan to provide an absolute energy calibration. XAS data reduction, as well as XANES linear combination analysis, was done in Athena while Artemis was used to fit EXAFS spectra.[19]

Near ambient (atmospheric) pressure X-ray photoelectron spectroscopy (NAP-XPS) was performed at the ISISS beamline of the synchrotron radiation facility BESSY II of the Helmholtz-Zentrum Berlin in a setup described elsewhere [20]. The $\mathrm{CoFe}_{2} \mathrm{O}_{4}$ NP powder was pressed into a self-supporting pellet, fixed on a sapphire holder and mounted inside the XPS reaction cell designed for in situ measurements. The heating of the samples was achieved by an infrared laser. The sample was pretreated in 0.5 mbar $\mathrm{O}_{2}$ at $573 \mathrm{~K}$ for $1 \mathrm{~h}$. For 2-propanol oxidation a 1:1 reaction mixture of 2-propanol and oxygen was introduced by calibrated mass flow controllers, the temperature was increased up to $573 \mathrm{~K}$ with a heating rate of $5 \mathrm{~K} \mathrm{~min}^{-1}$, and the photoemission spectra were acquired using selected photon energies that resulted in photoelectrons with $170 \mathrm{eV}$ kinetic energy and a $\sim 0.6 \mathrm{~nm}$ inelastic mean free path. After 
catalytic reaction the sample was again oxidatively treated in $0.5 \mathrm{mbar}_{2}$ at $573 \mathrm{~K}$ for several hours.

\subsection{Experimental procedures}

A stainless-steel microreactor set-up was used for the oxidation of 2-propanol. For catalytic tests the glass-lined stainless steel U-tube reactor was filled with $100 \mathrm{mg}$ of the catalyst sieve fraction $(250-355 \mu \mathrm{m})$. A thermocouple was directly placed in the catalyst bed for temperature control. Time-resolved quantitative online gas analysis was performed with a calibrated quadrupole mass spectrometer (QMS, Balzers GAM422). Dosing of 2-propanol was achieved by passing $\mathrm{He}$ through a saturator at $273 \mathrm{~K}$. By means of mixing valves, 2-propanol/ $\mathrm{He}$ and $\mathrm{O}_{2}$ were mixed and further diluted by He. All gas flows were adjusted by calibrated mass flow controllers (MFCs).

For the 2-propanol oxidation reaction $0.18 \%$ 2-propanol $/ 0.18 \% \mathrm{O}_{2} / \mathrm{He}$ feed gas was passed over the deactivated catalyst $(100 \mathrm{sccm})$ for $1 \mathrm{~h}$ and the sample was heated to $573 \mathrm{~K}$ with a heating rate of $0.5 \mathrm{~K} \mathrm{~min}$. Deactivation was induced by an initial oxidation run. The temperature was kept constant for $1 \mathrm{~h}$ before the sample was cooled to ambient temperature with $0.5 \mathrm{~K} \mathrm{~min}^{-1}$. The 2-propanol oxidation experiment was repeated directly without any further pretreatment. For the inhibition experiments, $\mathrm{CO}_{2}$, acetone or acetic acid was passed over the fresh catalyst until saturation of the sample was reached at room temperature. After purging the reactor with $\mathrm{He}$ for $1 \mathrm{~h}$, 2-propanol oxidation was performed over the saturated sample. For the $\mathrm{O}_{2}$ TPD experiment the fresh catalyst was heated to $723 \mathrm{~K}$ in $\mathrm{He}$ with a heating rate of $3 \mathrm{~K} \mathrm{~min}^{-1}$. Prior to each experiment, the catalyst was oxidatively pretreated in $10 \%$ $\mathrm{O}_{2} / \mathrm{He}$ or $10 \% \mathrm{~N}_{2} \mathrm{O} / \mathrm{He}$ (each $10 \mathrm{sccm}$ ) for $2 \mathrm{~h}$ at maximum temperatures in the range of 373 to $623 \mathrm{~K}(50 \mathrm{~K}$ steps $)$. Additionally, pretreatments in He atmosphere at 573 and $723 \mathrm{~K}$ were performed corresponding to a TPD experiment. After cooling to ambient temperature 2propanol oxidation was performed.

The DRIFTS experiment was performed with oxidatively pretreated $\mathrm{CoFe}_{2} \mathrm{O}_{4}$ NPs diluted with diamond powder (1:2). DRIFT spectra were acquired in a wavenumber range between 700 
and $4000 \mathrm{~cm}^{-1}$ during 2-propanol dehydrogenation at RT and $503 \mathrm{~K}$ for 30 min with subsequent desorption in inert gas and afterwards during oxidative pretreatment at $573 \mathrm{~K}$. The background spectra of the pretreated catalyst were recorded at RT, $503 \mathrm{~K}$ and $573 \mathrm{~K}_{\text {in }} \mathrm{N}_{2}(10 \mathrm{sccm})$.

\section{Results}

\subsection{Structural characterization}

The XRD patterns of the as-synthesized $\mathrm{CoFe}_{2} \mathrm{O}_{4}$ NPs are shown in Figure 1a. All reflections can be assigned to $\mathrm{CoFe}_{2} \mathrm{O}_{4}$ (PDF2 22-1086) indicating the presence of phase-pure cobalt-iron spinel NPs of $5 \mathrm{~nm}$ size determined by the Scherrer equation. From the TEM image shown in Figure $1 \mathrm{~b}$ the average particle size of $4 \mathrm{~nm}$ was derived. The small particle size was achieved due to the strong binding of oleylamine to the iron cations resulting in a strong capping effect which suppressed agglomeration and further particle growth. The results of the $\mathrm{N}_{2}$ physisorption measurements are summarized in Table 1 . The specific surface area is smaller than expected for spherical particles of 4-5 $\mathrm{nm}$ size. Assuming uniform spherical particles a particle size of 6-7 $\mathrm{nm}$ can be calculated from the specific surface area. In addition, the adsorption and desorption isotherms are shown in Figure S1. The observed hysteresis and consequential porosity arises not from the NP, but from the space between them as the interparticle voids are in good agreement with the NP size. Therefore, the isotherms are better described as type II than type IV isotherms, indicating non-porous particles.
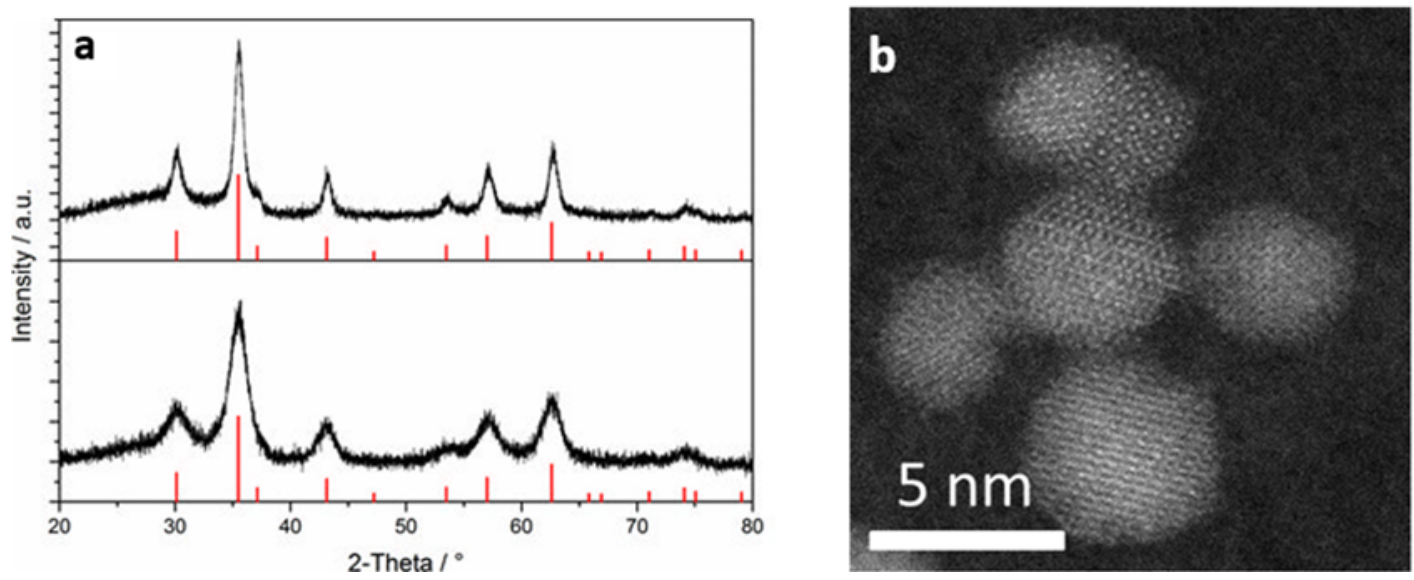
Figure 1. XRD patterns of $\mathrm{CoFe}_{2} \mathrm{O}_{4}$ NPs before (a, bottom) and after (a, top) calcination with the reference displayed as vertical lines in red $\left(\mathrm{CoFe}_{2} \mathrm{O}_{4}\right.$ PDF 22-1086). TEM image of $\mathrm{CoFe}_{2} \mathrm{O}_{4}$ NPs (b).

Table 1. Textural properties of the cobalt ferrite catalyst.

\begin{tabular}{ccccc}
\hline & $\begin{array}{c}\text { particle size } \\
/ \mathrm{nm}\end{array}$ & $\begin{array}{c}\text { specific surface } \\
\text { area }\end{array}$ & $\begin{array}{c}\text { pore volume } \\
/ \mathrm{cm}^{3} \mathrm{~g}^{-1}\end{array}$ & pore diameter \\
& & $\mathrm{m}^{2} \mathrm{~g}^{-1}$ & & \\
\hline $\mathrm{CoFe}_{2} \mathrm{O}_{4}$ & 4 & 170 & 0.16 & 3.9 \\
\hline
\end{tabular}

${ }^{\mathrm{a}}$ Mean particle size derived from TEM images.

\section{2. $\mathrm{O}_{2}$ Temperature-programmed desorption}
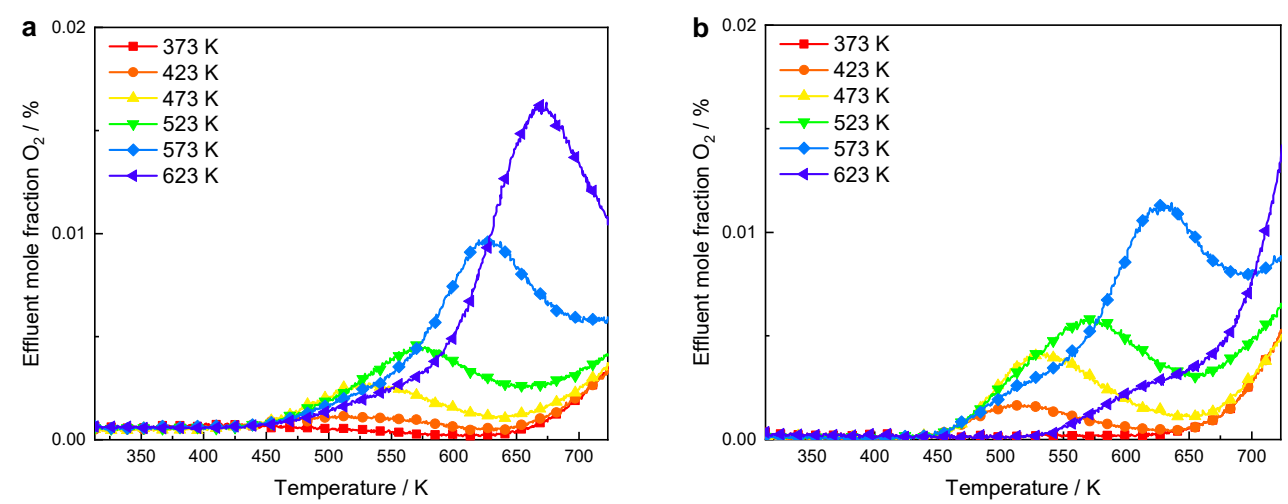

Figure 2. $\mathrm{O}_{2}$ TPD profiles of $\mathrm{CoFe}_{2} \mathrm{O}_{4} \mathrm{NPs}$ after pretreatment in $10 \% \mathrm{O}_{2} / \mathrm{He}$ (a) and $10 \%$ $\mathrm{N}_{2} \mathrm{O} / \mathrm{He}($ b) at $373,423,473,523,573$ and $623 \mathrm{~K}$.

To investigate the presence of reactive surface oxygen species on the $\mathrm{CoFe}_{2} \mathrm{O}_{4} \mathrm{NPs}, \mathrm{O}_{2}$ TPD experiments were performed with a variation of the pretreatment temperature in $10 \%$ $\mathrm{O}_{2} / \mathrm{He}$ and $10 \% \mathrm{~N}_{2} \mathrm{O} / \mathrm{He}$ (Figure 2). Independent of the pretreatment atmosphere, small amounts of $\mathrm{O}_{2}$ start to desorb around $423 \mathrm{~K}$ except for the NPs pretreated at $373 \mathrm{~K}$, where only at high temperatures $(<650 \mathrm{~K})$ desorption is observed. Molecular oxygen species like adsorbed $\mathrm{O}_{2}$, $\left(\mathrm{O}_{2}\right)^{-}$, or $\left(\mathrm{O}_{2}\right)^{2-}$ can be excluded due to the high onset temperature of desorption. Furthermore, the same onset temperatures were observed for the $\mathrm{N}_{2} \mathrm{O}$ pretreatment which cannot lead to molecular oxygen species. The increasing desorption at high temperatures 
indicates the beginning desorption of surface lattice oxygen. In between, each TPD profile exhibits a maximum, which increases in intensity and is shifted to higher temperatures with increasing pretreatment temperature. All desorption peak temperatures are the same for the corresponding pretreatment temperature with $\mathrm{O}_{2}$ or $\mathrm{N}_{2} \mathrm{O}$ indicating the formation of the same atomic oxygen species. The overall amounts of desorbed $\mathrm{O}_{2}$ are summarized in Table 2 . Depending on the pretreatment temperature the amount of desorbed $\mathrm{O}_{2}$ increases with increasing pretreatment temperature. However, the amount of desorbed $\mathrm{O}_{2}$ after the pretreatment in $\mathrm{O}_{2}$ is always lower compared with the amount detected after the $\mathrm{N}_{2} \mathrm{O}$ pretreatment indicating the potential of generating reactive atomic surface oxygen species on spinel surfaces by $\mathrm{N}_{2} \mathrm{O}$ decomposition. The highest amount of $77 \mu \mathrm{mol} \mathrm{g}_{\mathrm{cat}}{ }^{-1}$ of desorbed $\mathrm{O}_{2}$ corresponds roughly to $10 \%$ of the amount of outermost surface oxygen atoms of the most stable (100), (110), and (111) $\mathrm{CoFe}_{2} \mathrm{O}_{4}$ surface facets (SI).

Table 2. Amounts of desorbed $\mathrm{O}_{2}$ during the $\mathrm{O}_{2}$ TPD experiments after oxidative pretreatment in $10 \% \mathrm{O}_{2} / \mathrm{He}$ and $10 \% \mathrm{~N}_{2} \mathrm{O} / \mathrm{He}$.

\begin{tabular}{ccc}
\hline Pretreatment temperature / & \multicolumn{2}{c}{$\mathbf{O}_{\mathbf{2}}$ amount / $\boldsymbol{m m o l ~}_{\text {cat }}{ }^{-1}$} \\
\cline { 2 - 3 } & $\mathbf{O}_{\mathbf{2}}$ pretr. & $\mathbf{N}_{\mathbf{2}} \mathbf{O}$ pretr. \\
\hline 373 & 8 & 20 \\
423 & 10 & 27 \\
473 & 12 & 36 \\
523 & 16 & 43 \\
573 & 25 & 57 \\
623 & 35 & 77 \\
\hline
\end{tabular}

\subsection{2-Propanol oxidation}

The initial 2-propanol oxidation run using a 1:1 ratio of 2-propanol to $\mathrm{O}_{2}$ was performed after oxidative pretreatment at $573 \mathrm{~K}$. The high degrees of conversion and yields of acetone shown in Figure 3 identify $\mathrm{CoFe}_{2} \mathrm{O}_{4}$ NPs as both active and selective catalyst for the oxidation of 2-propanol. The conversion profiles during heating exhibit three maxima at 430, 510, and $573 \mathrm{~K}$. At the low-temperature maximum the ratio between 2-propanol and $\mathrm{O}_{2}$ conversion is 
2:1, indicating the oxidative dehydrogenation of 2-propanol to acetone (eq. 1), and decreases at higher temperatures due to the dehydration (eq. 2) and total oxidation (eq. 3) reactions. Correspondingly, the selectivity decreases as $\mathrm{CO}_{2}$ and propene are formed in small amounts at the intermediate maximum and reach their maxima at the maximum temperature of $573 \mathrm{~K}$. In addition, $\mathrm{H}_{2} \mathrm{O}$ is formed during all reactions. The activity at lower temperatures was neither detected during cooling nor in the subsequent second oxidation run (Figure 3b). These finding indicate the deactivation of the low-temperature pathway, whereas the high-temperature reaction pathway remains stable. During the second run only a small additional degree of deactivation is observed and also the long-term stability test at $573 \mathrm{~K}$ (Figure S2) did not show any loss of activity or selectivity during $90 \mathrm{~h}$ time-on-stream.

$$
\begin{gathered}
2\left(\mathrm{CH}_{3}\right)_{2} \mathrm{CHOH}+\mathrm{O}_{2} \rightarrow 2\left(\mathrm{CH}_{3}\right)_{2} \mathrm{CO}+2 \mathrm{H}_{2} \mathrm{O} \\
\left(\mathrm{CH}_{3}\right)_{2} \mathrm{CHOH} \rightarrow \mathrm{CH}_{2}=\mathrm{CHCH}_{3}+\mathrm{H}_{2} \mathrm{O} \\
2\left(\mathrm{CH}_{3}\right)_{2} \mathrm{CHOH}+9 \mathrm{O}_{2} \rightarrow 6 \mathrm{CO}_{2}+8 \mathrm{H}_{2} \mathrm{O}
\end{gathered}
$$

Overall, the catalytic properties of the $\mathrm{CoFe}_{2} \mathrm{O}_{4}$ NPs in 2-propanol oxidation are similar to the previously studied $\mathrm{Co}_{3} \mathrm{O}_{4}$ NPs. The conversion maxima occur at exactly the same temperatures and also the inhibition of the low-temperature activity is observed after the initial 2-propanol oxidation run. However, the activity of the $\mathrm{Co}_{3} \mathrm{O}_{4} \mathrm{NPs}$ is higher reaching nearly full conversion with $100 \%$ selectivity to acetone at the low-temperature maximum. In addition, even at higher temperatures, propene formation is not detected.
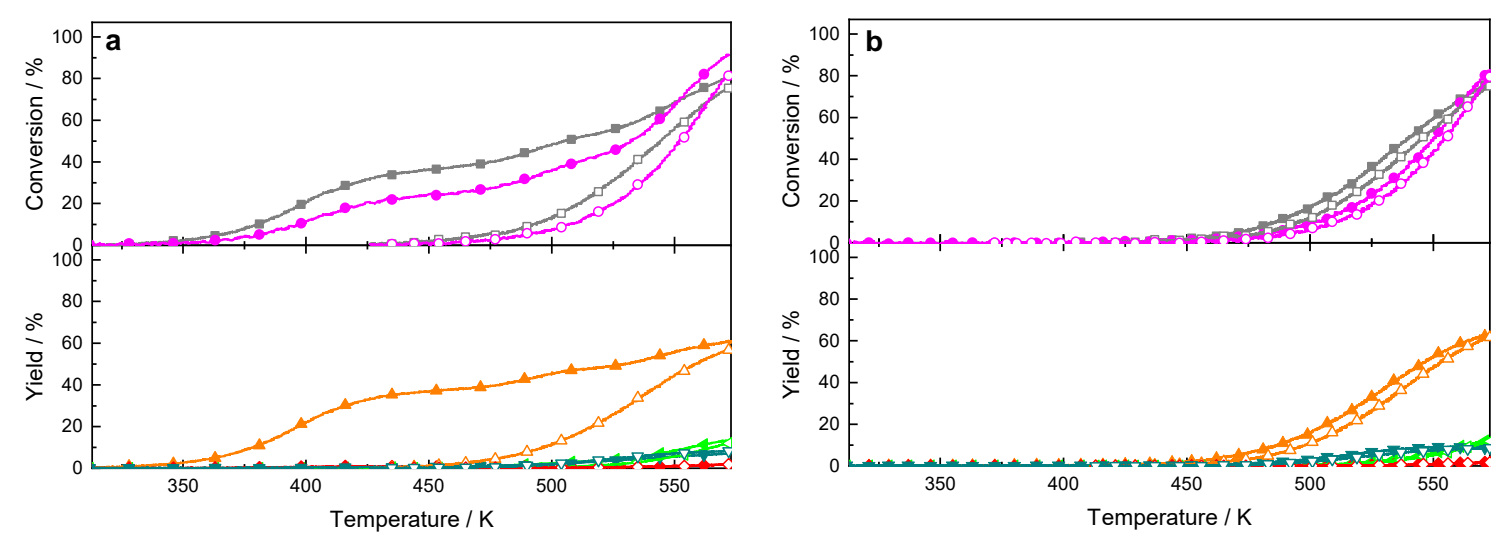
Figure 3. Conversion and yields during the (a) first and (b) subsequent second (lighter colors) 2propanol oxidation over $\mathrm{CoFe}_{2} \mathrm{O}_{4}$ NPs. Conversion of $\left(\mathrm{CH}_{3}\right)_{2} \mathrm{CHOH}(\bullet)$ and $\mathrm{O}_{2}(\bullet)$ and yields of $\left(\mathrm{CH}_{3}\right)_{2} \mathrm{CO}(\triangle), \mathrm{CH}_{2}=\mathrm{CHCH}_{3}(\nabla), \mathrm{CO}_{2}(\varangle)$ and $\mathrm{H}_{2}(\diamond)$. Traces with full symbols were obtained during heating and traces with hollow symbols during cooling.

2-Propanol oxidation over deactivated $\mathrm{CoFe}_{2} \mathrm{O}_{4}$ NPs was performed after oxidative pretreatment in $10 \% \mathrm{O}_{2} / \mathrm{He}$ and $\mathrm{N}_{2} \mathrm{O} / \mathrm{He}$ at temperatures between 373 and $623 \mathrm{~K}$. Deactivation was induced by the initial 2-propanol oxidation run after oxidative pretreatment at $573 \mathrm{~K}$ and corresponds to the measurement within the pretreatment temperature variation. The degrees of conversion of 2-propanol and $\mathrm{O}_{2}$ are shown in Figure 4. 2-Propanol oxidation after $\mathrm{O}_{2}$ pretreatment at $373 \mathrm{~K}$ and $423 \mathrm{~K}$ exhibits no low-temperature activity and matches with the second oxidation run (Figure $3 \mathrm{~b}$ ), whereas at $473 \mathrm{~K}$ a slightly enhanced activity around $510 \mathrm{~K}$ is observed. Further increasing pretreatment temperatures $(523-623 \mathrm{~K})$ led to the formation of a low-temperature activity around $430 \mathrm{~K}$ and an additional intermediate maximum at $510 \mathrm{~K}$. At the maximum temperature of $573 \mathrm{~K}$, a third maximum is detected for all measurements regardless of the pretreatment temperature, reaching a 2-propanol conversion between $80-82 \%$ after pretreatment at temperatures $\geq 523 \mathrm{~K}$, while the measurements without low-temperature activity show slightly lower conversion around $75 \%$. In accordance with 2-propanol, the same dependence on the pretreatment temperature is observed for the degrees of $\mathrm{O}_{2}$ conversion.

The corresponding yields of the 2-propanol oxidation products acetone, propene, and $\mathrm{CO}_{2}$ are shown in Figure S3. The yields of acetone follow the trend of 2-propanol conversion with regard to position and occurrence of the low-temperature maxima at which acetone is formed with $100 \%$ selectivity. At the maximum reaction temperature, acetone yields of $72 \%$ (623 K), $66 \%(523,573 \mathrm{~K})$, and around $62 \%(373,423,473 \mathrm{~K})$ are obtained. The $\mathrm{CO}_{2}$ yields are between 12 and $15 \%$ and increase with increasing pretreatment temperature, whereas propene yields of 3-9\% are reached with the trend being reversed, i.e. decreasing with increasing pretreatment temperature. 

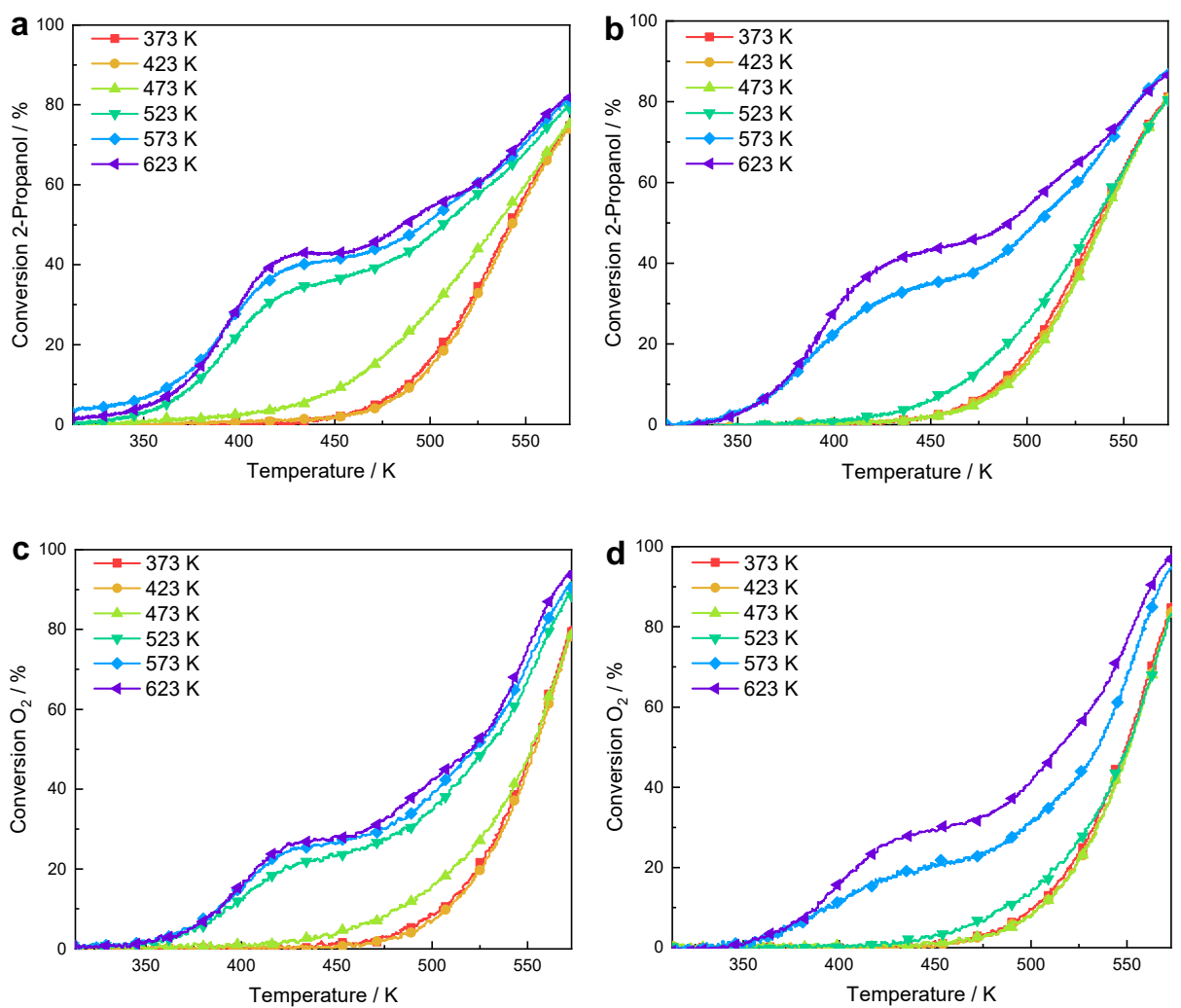

Figure 4. Conversion of $\left(\mathrm{CH}_{3}\right)_{2} \mathrm{CHOH}(\mathrm{a}, \mathrm{b})$ and $\mathrm{O}_{2}(\mathrm{c}, \mathrm{d})$ during 2-propanol oxidation over $\mathrm{CoFe}_{2} \mathrm{O}_{4} \mathrm{NPs}$ pretreated in $10 \% \mathrm{O}_{2} / \mathrm{He}(\mathrm{a}, \mathrm{c})$ and $10 \% \mathrm{~N}_{2} \mathrm{O} / \mathrm{He}(\mathrm{b}, \mathrm{d})$ at $373,423,473,523,573$ and $623 \mathrm{~K}$, respectively.

In comparison, the same selectivity trends are observed for 2-propanol oxidation after the $\mathrm{N}_{2} \mathrm{O}$ pretreatments: three conversion maxima at the same temperatures for the activated $\mathrm{CoFe}_{2} \mathrm{O}_{4} \mathrm{NPs}$, no low-temperature activity for low pretreatment temperatures, and a slightly increasing activity for the sample pretreated $50 \mathrm{~K}$ below the pretreatment temperature needed for full regeneration of the low temperature reaction pathway. However, the regeneration process is shifted by $50 \mathrm{~K}$ to higher temperatures so that pretreatment temperatures $\geq 573 \mathrm{~K}$ for $\mathrm{N}_{2} \mathrm{O}$ are needed to also oxidatively dehydrogenate 2-propanol to acetone and $\mathrm{H}_{2} \mathrm{O}$ around 430 K. Overall, after each oxidation the low-temperature reaction pathway is inhibited again for a subsequent 2-propanol oxidation run.

\subsection{Oxidative and inert pretreatment}


To investigate the influence of remaining adsorbates on the deactivated $\mathrm{CoFe}_{2} \mathrm{O}_{4} \mathrm{NPs}$, TPO experiments corresponding to the pretreatment for 2-propanol oxidation described above were performed and are exemplarily shown for both oxidizing atmospheres at 573 and $623 \mathrm{~K}$ in Figure $\mathrm{S} 4$. For the $\mathrm{O}_{2}$ pretreatment the $\mathrm{O}_{2}$ consumption always coincides with the maximum of $\mathrm{CO}_{2}$ and $\mathrm{H}_{2} \mathrm{O}$ formation. The same applies to $\mathrm{N}_{2} \mathrm{O}$ consumption with an additional maximum for $\mathrm{N}_{2}$ formation, but for the $\mathrm{N}_{2} \mathrm{O}$ pretreatment at $623 \mathrm{~K}$ the desorption of $\mathrm{O}_{2}$ is observed right after the $\mathrm{CO}_{2}$ signal declined. These results imply that $\mathrm{CoFe}_{2} \mathrm{O}_{4}$ NPs are active for $\mathrm{N}_{2} \mathrm{O}$ decomposition first oxidizing surface adsorbates to $\mathrm{CO}_{2}$ and after full regeneration forming $\mathrm{O}_{2}$. However, $\mathrm{O}_{2}$ formation is not detected for the pretreatment at $573 \mathrm{~K}$, as a great tailing for the adsorbate oxidation reaction is observed indicating incomplete regeneration. This can be also seen in the total amounts of $\mathrm{CO}_{2}$ formed, which are summarized in Table 3: for $623 \mathrm{~K} 1627$ $\mu \mathrm{mol} \mathrm{g} \mathrm{cat}^{-1} \mathrm{CO}_{2}$ are formed, whereas for $573 \mathrm{~K} 1422 \mu \mathrm{mol} \mathrm{g}_{\mathrm{cat}}{ }^{-1} \mathrm{CO}_{2}$ are detected. During the $\mathrm{O}_{2}$ pretreatment adsorbate oxidation is already observed at low temperatures and strongly increases up to $1985 \mu \mathrm{mol} \mathrm{g}_{\mathrm{cat}}{ }^{-1}$ at $573 \mathrm{~K}$. The difference in the maximum desorbing amounts can be explained by aging occurring on the long-term time scale over all conducted experiments, as the $\mathrm{N}_{2} \mathrm{O}$ experiments were performed prior to the $\mathrm{O}_{2}$ experiments. However, the $\mathrm{CO}_{2}$ amount during TPO experiments seems to be a good descriptor for the successful regeneration and occurrence of the low-temperature reaction pathway.

Table 3. Amounts of desorbing $\mathrm{CO}_{2}$ during the TPO experiments subsequent to 2-propanol oxidation performed after pretreatment in $10 \% \mathrm{O}_{2} / \mathrm{He}$ and $10 \% \mathrm{~N}_{2} \mathrm{O} / \mathrm{He}$.

\begin{tabular}{ccc}
\hline Pretreatment temperature / & \multicolumn{2}{c}{$\mathbf{C O}_{\mathbf{2}}$ amount / $\mathbf{\mu m o l} \mathbf{g}_{\text {cat }}{ }^{-1}$} \\
\cline { 2 - 3 } $\mathbf{K}$ & $\mathbf{O}_{\mathbf{2}}$ pretr. & $\mathbf{N}_{\mathbf{2}} \mathbf{O}$ pretr. \\
\hline 373 & 9 & 0 \\
423 & 23 & 0 \\
473 & 258 & 0 \\
523 & 1936 & 95 \\
573 & 1985 & 1422 \\
623 & 1795 & 1627 \\
\hline
\end{tabular}


In addition to the desorption of $\mathrm{CO}_{2}$ and $\mathrm{H}_{2} \mathrm{O}$, small amounts of 2-propanol, acetone, and propene $\left(\leq 22 \mu \mathrm{mol} \mathrm{gcat}^{-1}\right)$ were detected. Therefore, also an inert pretreatment in He was performed corresponding to a TPD experiment to investigate the influence of just desorbing adsorbates on the catalytic activity. A comparison of the effluent mole fractions during the $\mathrm{O}_{2}$ TPO experiment and pretreatment in He at $573 \mathrm{~K}$ is shown in Figure S5. For both pretreatments, a similar behavior is observed as $\mathrm{CO}_{2}, \mathrm{H}_{2} \mathrm{O}$, 2-propanol, and acetone start to desorb at $334 \mathrm{~K}$. For 2-propanol and acetone, two maxima are observed, which coincide regarding the temperature. Additional maxima for propene and $\mathrm{H}_{2}$ desorption are detected at 536 and $567 \mathrm{~K}$, respectively. However, the signals of $\mathrm{CO}_{2}$ and $\mathrm{H}_{2} \mathrm{O}$ in the $\mathrm{He}$ pretreatment are not as symmetric as the ones in the TPO experiment showing an increased tailing after reaching $573 \mathrm{~K}$. Although the same desorbing species are detected, the desorbing amounts summarized in Table S1 differ significantly: the amount of desorbing $\mathrm{CO}_{2}$ is approximately 12 times higher in the TPO experiment.

In addition, He pretreatments were extended to 523 and $723 \mathrm{~K}$ with subsequent 2-propanol oxidation. The 2-propanol degrees of conversion during the oxidation reaction after $\mathrm{He}$ pretreatment are shown in Figure S6 with references after oxidative pretreatment at 373, 473, and $573 \mathrm{~K}$. After He pretreatment at $523 \mathrm{~K}$, low-temperature activity was not observed. The catalytic behavior in the 2-propanol conversion after the He pretreatment at $573 \mathrm{~K}$ is similar to the behavior after oxidative pretreatment at $473 \mathrm{~K}$. Only small deviations in conversion around $510 \mathrm{~K}$ are observed and can be ascribed to a higher degree of regeneration of the intermediate activity maximum. In contrast, low-temperature activity is only observed after He pretreatment at $723 \mathrm{~K}$, but is not fully recovered compared with the oxidative pretreatment at $573 \mathrm{~K}$. The corresponding amounts of desorbing $\mathrm{CO}_{2}$ are summarized in Table $\mathrm{S} 2$ and confirm the trend observed during oxidative pretreatment: the increase in low-temperature activity during 2propanol oxidation coincides with an increasing amount of desorbing $\mathrm{CO}_{2}$.

\subsection{Inhibition experiments}


The influence of product inhibition was investigated by pre-adsorbing the main products $\mathrm{CO}_{2}$ and acetone. As acetone can lead to acetate species as possible reaction intermediates, also acetic acid was pre-adsorbed to generate adsorbed acetates groups on the $\mathrm{CoFe}_{2} \mathrm{O}_{4} \mathrm{NPs}$ prior to 2-propanol oxidation. $\mathrm{CO}_{2}$, acetone, and acetic acid were adsorbed at room temperature for $1 \mathrm{~h}$ subsequent to oxidative pretreatment at $573 \mathrm{~K}$. The degrees of conversion after adsorption are shown in Figure 5 and compared to the conversion achieved with the activated ( $1^{\text {st }}$ run) and deactivated $\left(2^{\text {nd }}\right.$ run) NPs. The adsorption of $\mathrm{CO}_{2}$ did not lead to any changes in the 2-propanol conversion compared with the $1^{\text {st }}$ run and is not displayed for clarity. The degrees of conversion at high temperatures are equal for both the adsorption of acetone and acetic acid in comparison to the activated catalyst. However, the conversion at high temperatures is slightly lower for the $2^{\text {nd }}$ run. After adsorption of acetic acid, the low- and intermediate-temperature activity is no longer observed, resulting in a shifted conversion of 2-propanol starting around $423 \mathrm{~K}$. The conversion profile corresponds to the conversion over the deactivated catalyst until a strong increase is observed at $475 \mathrm{~K}$, and above $530 \mathrm{~K}$ the conversion coincides with the conversion of the $1^{\text {st }}$ run. Pre-adsorption of acetone influences 2-propanol conversion in a different manner. The low- and intermediate-temperature activity maxima are observed and the conversion exhibits a similar trend as the catalyst without pre-adsorption. Nevertheless, the lowtemperature activity is shifted to higher temperatures and conversion is lower after acetone adsorption. Again, regardless of the adsorbed species, the low-temperature activity is inhibited after a subsequent oxidation run. Thus, adsorbed acetate was identified as inhibiting species.

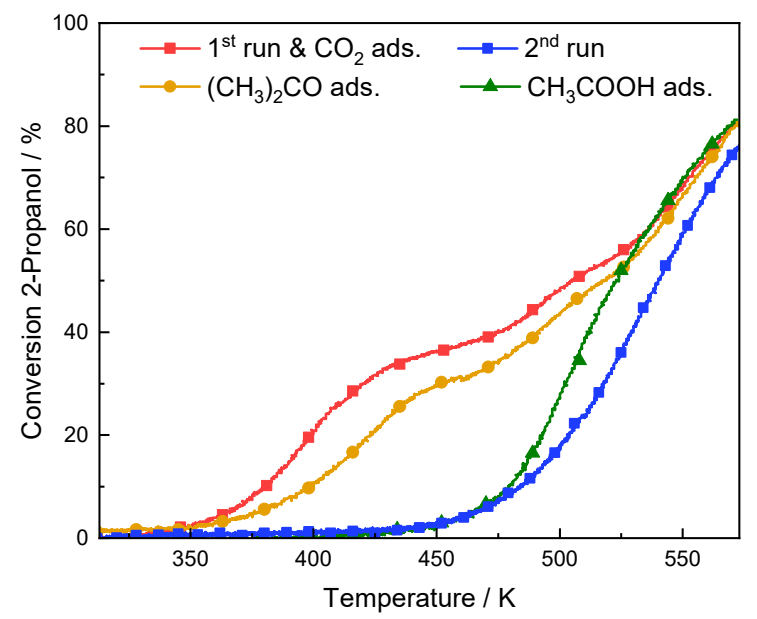


Figure 5. Conversion during 2-propanol oxidation over $\mathrm{CoFe}_{2} \mathrm{O}_{4} \mathrm{NPs}$ pretreated in $10 \% \mathrm{O}_{2} / \mathrm{He}$ ( $1^{\text {st }}$ run) and subsequent adsorption of $\mathrm{CO}_{2},\left(\mathrm{CH}_{3}\right)_{2} \mathrm{CO}$, and $\mathrm{CH}_{3} \mathrm{COOH}$ as well as over deactivated $\mathrm{CoFe}_{2} \mathrm{O}_{4} \mathrm{NPs}\left(2^{\text {nd }}\right.$ run $)$.

\subsection{In situ DRIFT spectroscopy}

In situ DRIFTS experiments were performed to investigate the intermediates formed during the interaction of 2-propanol with the $\mathrm{CoFe}_{2} \mathrm{O}_{4} \mathrm{NPs}$ and for the identification of species remaining on the catalyst surface after reaction. The DRIFT spectra during adsorption and desorption of 2-propanol at ambient temperature are shown in Figure 6. All bands observed after adsorption of 2-propanol can be assigned to gas-phase 2-propanol and adsorbed 2propoxide, except for the negative band at $3681 \mathrm{~cm}^{-1}$ which indicates the consumption of surface $\mathrm{OH}$ groups. For both species, bands in the same wavenumber regions were detected and lead to superimposition. However, bands at 3654,1252 , and $1087 \mathrm{~cm}^{-1}$ can be assigned to v(O$\mathrm{H}), \delta(\mathrm{O}-\mathrm{H})$, and $v(\mathrm{C}-\mathrm{O})$ of gas-phase 2-propanol, whereas bands at 2971 and $2888 \mathrm{~cm}^{-1}$ can be assigned to $v(\mathrm{C}-\mathrm{H})$ of adsorbed and gas-phase 2-propanol, respectively.[21,22] In addition, the bands at $1473,1382,1338,1163$, and $1136 \mathrm{~cm}^{-1}$ can be assigned to $\delta_{\text {as }}\left(\mathrm{CH}_{3}\right), \delta_{\mathrm{s}}\left(\mathrm{CH}_{3}\right), \delta(\mathrm{C}-\mathrm{H})$, $v(\mathrm{C}-\mathrm{C})$, and $v(\mathrm{C}-\mathrm{O})$ of adsorbed 2-propanol, respectively.[21,23,24] Due to the superimposition by gas-phase 2-propanol, desorption at room temperature was performed. The bands of gasphase 2-propanol were no longer observed, and the 2-propoxide bands at 2971, 2888, and 1382 $\mathrm{cm}^{-1}$ became less intense during the desorption experiment. As no other band emerged, 2propoxide is the only species detected after 2-propanol adsorption at room temperature on the NP surface.

The DRIFT spectra during the adsorption and desorption experiments at $503 \mathrm{~K}$ are also shown in Figure 6. Again, all bands for gas-phase 2-propanol and 2-propoxide are observed. However, new bands emerge at 2958, 1735, and $1228 \mathrm{~cm}^{-1}$, which can be assigned to $v(\mathrm{C}-\mathrm{H})$, $v(\mathrm{C}=\mathrm{O})$, and $v(\mathrm{C}-\mathrm{C})$ of acetone, respectively, indicating 2-propanol dehydrogenation.[23-26] So, bands like $\delta_{\text {as }}\left(\mathrm{CH}_{3}\right)$ and $\delta_{\mathrm{s}}\left(\mathrm{CH}_{3}\right)$, which were previously only assigned to gas-phase 2propanol and 2-propoxide, also emerge from formed acetone. Additional weak bands around 
1555 and $1309 \mathrm{~cm}^{-1}$ are detected and indicate the formation of surface carbonates.[9] During the desorption at $503 \mathrm{~K}$ all bands can still be observed at the beginning of the desorption experiments. However, during the desorption experiments all previously observed bands disappeared and only two bands at 1402 and $1333 \mathrm{~cm}^{-1}$ remained in the DRIFT spectra, which were superimposed by the $\delta_{\mathrm{s}}\left(\mathrm{CH}_{3}\right)$ band at $1373 \mathrm{~cm}^{-1}$. The former remaining band at $1402 \mathrm{~cm}^{-1}$ can be identified as the $v_{\mathrm{s}}(\mathrm{COO})$ stretching observed for carboxylate groups, whereas the band at $1333 \mathrm{~cm}^{-1}$ can be assigned to $\delta\left(\mathrm{CH}_{3}\right)$ of acetate species.[10,11,22,27]
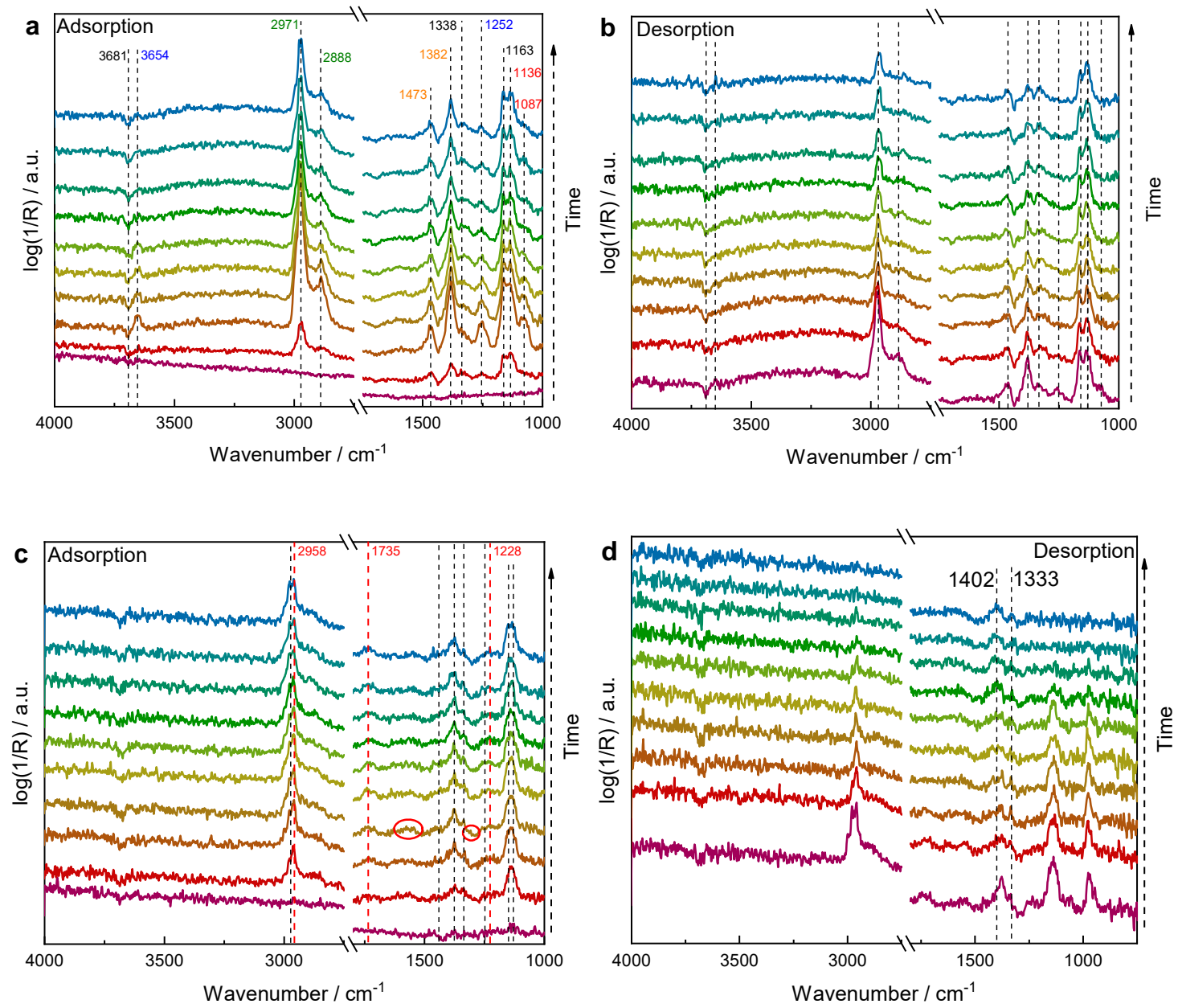

Figure 6. DRIFT spectra during adsorption $(\mathrm{a}, \mathrm{c})$ and desorption $(\mathrm{b}, \mathrm{d})$ of 2-propanol on $\mathrm{CoFe}_{2} \mathrm{O}_{4}$ NPs at ambient temperature (a,b) and $503 \mathrm{~K}(\mathrm{c}, \mathrm{d})$.

The oxidative treatment of the $\mathrm{CoFe}_{2} \mathrm{O}_{4} \mathrm{NPs}$ after desorption at $503 \mathrm{~K}$ is shown in Figure 7. Only bands of the stable acetate species were observed at the beginning, but started to disappear in the oxidizing atmosphere. In parallel, the formation of bands at 2360 and $2330 \mathrm{~cm}^{-1}$ due to 
the presence of gas-phase $\mathrm{CO}_{2}$ and weak bands at 1555,1309 , and $1259 \mathrm{~cm}^{-1}$ were detected, which can be assigned to adsorbed carbonate species. An additional band of $\delta\left(\mathrm{H}_{2} \mathrm{O}\right)$ at $1624 \mathrm{~cm}^{-}$ ${ }^{1}$ is observed. The acetate bands at 1402 and $1333 \mathrm{~cm}^{-1}$ became negative, and the intensity decreased until only small amounts of gas-phase $\mathrm{CO}_{2}$ remained. Simultaneously, the band at $3681 \mathrm{~cm}^{-1}$ started to emerge indicating the formation of $\mathrm{OH}$ groups, which had been consumed during 2-propanol adsorption at RT.

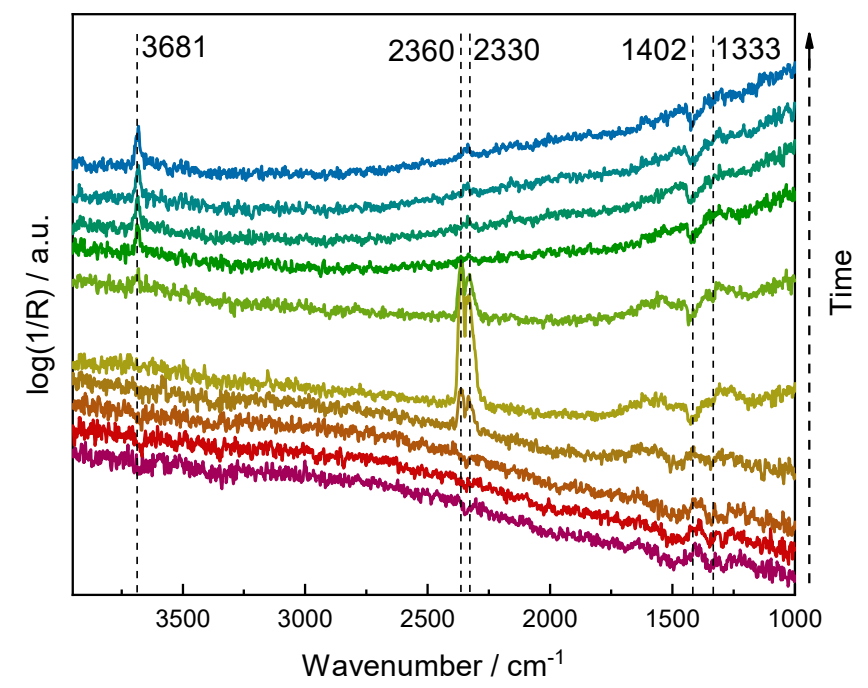

Figure 7. DRIFT spectra during oxidative treatment subsequent to the exposure of the $\mathrm{CoFe}_{2} \mathrm{O}_{4}$ NPs to 2-propanol at $503 \mathrm{~K}$.

After identification of the acetate and carbonate species in addition to the reactant and product species during interaction of 2-propanol with the spinel surface, a ratio between acetates and carbonates is estimated by using the amounts of $\mathrm{H}_{2}, \mathrm{H}_{2} \mathrm{O}$, and $\mathrm{CO}_{2}$ (Table S1) desorbed during the pretreatment of the deactivated $\mathrm{CoFe}_{2} \mathrm{O}_{4} \mathrm{NPs}$ at $573 \mathrm{~K}$ in $10 \% \mathrm{O}_{2} / \mathrm{He}$ (Figure S5). Considering all $\mathrm{H}$-atoms originating from acetate species, desorbing $\mathrm{O}$ - and $\mathrm{C}$-atoms remain, which can be attributed to the carbonate species. With the total amounts, a ratio of 5.5 to 1 between acetates and carbonates was calculated. However, after attributing all $\mathrm{H}$ - and $\mathrm{O}$-atoms to the surface adsorbates, residual $\mathrm{C}$-atoms are still left within the calculation, indicating the formation of elemental carbon during the 2-propanol oxidation reaction. The remaining $\mathrm{C}$-atoms could further be oxidized by the gas-phase oxygen which consumed amount sums up to 1690 
$\mu \mathrm{mol} \mathrm{g}_{\mathrm{cat}}{ }^{-1}$. However, more oxygen is consumed than theoretically is needed for the residual carbon oxidation to $\mathrm{CO}_{2}$. The remaining consumed oxygen can then reoxidize the catalyst surface. Considering the three most stable surface terminations (100), (110), and (111) a degree of surface reduction of $0.3 \%$ was calculated, indicating almost no reduction of the $\mathrm{CoFe}_{2} \mathrm{O}_{4}$ surface during 2-propanol oxidation.

\subsection{X-ray photoelectron spectroscopy}

For providing evidence for carbon formation on the $\mathrm{CoFe}_{2} \mathrm{O}_{4}$ surface, XPS C 1s spectra of the catalyst before and after 2-propanol oxidation were recorded. In Figure 8 the peak at 284.5 $\mathrm{eV}$ is assigned to carbon and becomes more intense for the catalyst after reaction. Additionally, the peak at $288.2 \mathrm{eV}$ is often reported for surface carbonates [9] and is also slightly increasing supporting the DRIFTS results. Because of the ex situ performed measurements the small changes might occur due to the exposure to air during the just in time transfer to the XPS set-up. Therefore, in situ NAP-XPS measurements were performed using another $\mathrm{CoFe}_{2} \mathrm{O}_{4} \mathrm{NP}$ sample during oxidative pretreatment and 2-propanol oxidation at $573 \mathrm{~K}$. The increased intensity of the carbon peak in the $\mathrm{C} 1 \mathrm{~s}$ spectra reveals carbon formation during the oxidation reaction. Posttreatment of the catalyst under an oxidative atmosphere for several hours resulted in complete oxidation of all surface carbon species.

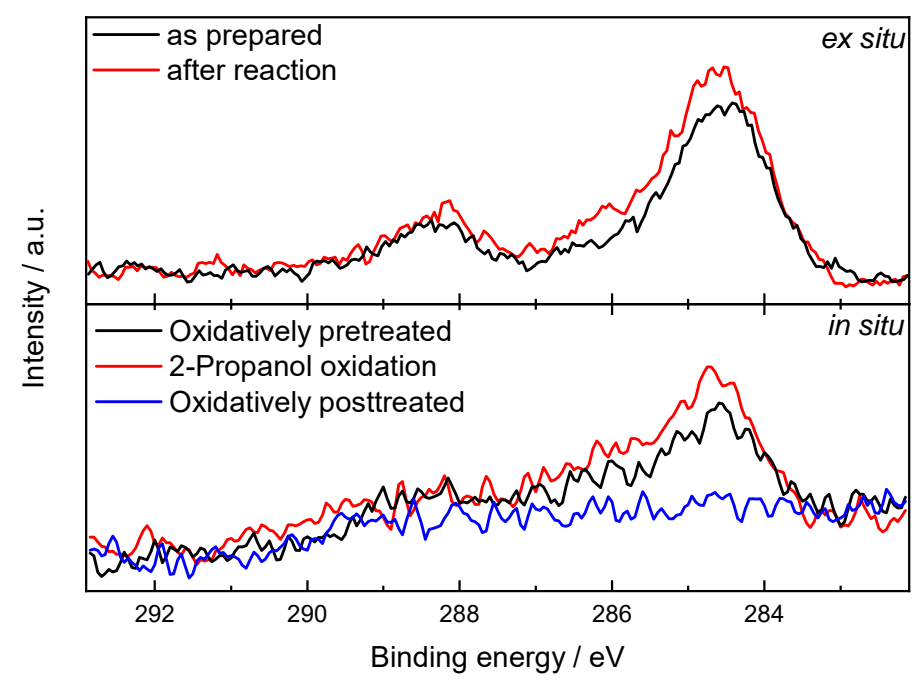


Figure 8. C 1s spectra of $\mathrm{CoFe}_{2} \mathrm{O}_{4}$ NPs measured ex situ (top) before and after 2-propanol oxidation as well as in situ (bottom).

To further examine changes in the surface composition with the focus on the cobalt oxidation state and reactive surface oxygen species, the $\mathrm{CoFe}_{2} \mathrm{O}_{4} \mathrm{NPs}$ were analyzed by XPS before and after 2-propanol oxidation. The cobalt oxidation states were investigated by monitoring the Co $2 p$ region $\left(2 p_{3 / 2}\right.$ and $2 p_{1 / 2}$ peaks as well as the corresponding shake-up satellites) as shown in Figure S7. Usually $\mathrm{Co}^{2+}$ exhibits an intense shake-up satellite at $786 \mathrm{eV}$ as is observed for the $\mathrm{CoFe}_{2} \mathrm{O}_{4} \mathrm{NPs}$, whereas for $\mathrm{Co}^{3+}$ only a weak satellite peak is formed at $790 \mathrm{eV}$. Therefore, the Co $2 \mathrm{p}_{3 / 2}$ peak at $779 \mathrm{eV}$ and the satellite peak around $787 \mathrm{eV}$ were deconvoluted using four peaks as summarized in Table S3 and reported in the literature.[28,29] The comparison of the energy difference $(\Delta \mathrm{E})$ between the $2 \mathrm{p}_{3 / 2}$ and the $2 \mathrm{p}_{1 / 2}$ peaks can be used to examine changes in the cobalt oxidation state.[30] For the $\mathrm{CoFe}_{2} \mathrm{O}_{4}$ NPs the energy differences between the $2 p_{3 / 2}$ and $2 p_{1 / 2}$ peaks are summarized in Table 4 and reveal a dominant contribution of $\mathrm{Co}^{2+} \cdot[31]$ The higher energy difference after 2-propanol oxidation indicates a small enrichment of $\mathrm{Co}^{2+}$ on the surface. Taking the deconvolution curves for $\mathrm{CoFe}_{2} \mathrm{O}_{4}$ into account, the intensity ratio of the Co $2 \mathrm{p}_{3 / 2}$ peak and the corresponding satellite $\left(\mathrm{I}_{\mathrm{p} / \mathrm{s}}\right)$ can be evaluated. The slightly decreased intensity ratio for the Co $2 p$ spectra after reaction also indicates a higher $\mathrm{Co}^{2+}$ content despite the exposure to air during transfer to the XPS set-up.

In contrast to the changes in the Co $2 p$ region, the $\mathrm{Fe} 2 \mathrm{p}$ region (Figure $\mathrm{S} 8$ ) with the $2 p_{3 / 2}$ and $2 p_{1 / 2}$ peaks as well as the corresponding shake-up satellites assigned to $\mathrm{Fe}^{3+}$ was not affected at all by 2-propanol oxidation. Additionally, only minor changes in the $\mathrm{O} 1 \mathrm{~s}$ spectra (Figure S9) were observed.

Table 4. Binding energies of the Co $2 \mathrm{p}_{3 / 2}$ and $2 \mathrm{p}_{1 / 2}$ peaks, corresponding energy differences $(\Delta \mathrm{E})$, and intensity ratios of the Co $2 \mathrm{p}_{3 / 2}$ peak and the corresponding satellite $\left(\mathrm{I}_{\mathrm{p} / \mathrm{s}}\right)$ before and after reaction for $\mathrm{CoFe}_{2} \mathrm{O}_{4} \mathrm{NPs}$.

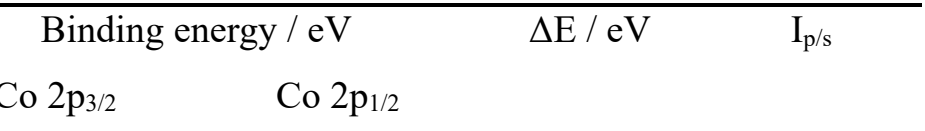




\begin{tabular}{ccccc}
$\mathrm{CoFe}_{2} \mathrm{O}_{4}$ before reaction & 779.9 & 795.3 & 15.4 & 1.19 \\
$\mathrm{CoFe}_{2} \mathrm{O}_{4}$ after reaction & 779.8 & 795.5 & 15.7 & 1.17 \\
\hline
\end{tabular}

\subsection{X-ray absorption spectroscopy}

Operando XAS was applied to extract information about the evolution of the chemical state and structure of the catalysts in the presence of 2-propanol. Both Co K-edge and Fe K-edge Xray absorption near edge structure (XANES) data of the as-prepared $\mathrm{CoFe}_{2} \mathrm{O}_{4} \mathrm{NPs}$ are in a close resemblance with a reference cobalt ferrite spectrum measured at the same beamline. In the XANES spectra a shoulder at ca. $7723 \mathrm{eV}$ was found to develop during the first reaction step at $473 \mathrm{~K}$, indicating the formation of $\mathrm{CoO}$ (Figure 9a). Linear combination analysis (LCA) of the XANES data revealed 25 at. $\%$ of $\mathrm{Co}$ in the $\mathrm{CoO}$ phase at $473 \mathrm{~K}$, which remains during the following reaction steps at 523 and $573 \mathrm{~K}$. An example of the LCA procedure can be found in the supporting information (Figure S16). This finding is also corroborated by the information extracted from the Co K-edge extended X-ray absorption fine structure (EXAFS) spectra. Thus, the Co-O feature shifts from 1.5 to $1.55 \AA^{-1}$ (uncorrected for phase shift, Figure $9 \mathrm{~b}$ ), while the peak at $2.55 \AA^{-1}$ (uncorrected) decreases and becomes broader. The latter can be assigned to CoCo backscattering and has to be considered along with the shoulder $3.1 \AA^{-1}$ (uncorrected), which corresponds to Co-Fe backscattering and can be considered a fingerprint of the spinel structure. As can be seen from the EXAFS spectra, the amount of Co in the spinel phase decreases substantially in the presence of 2-propanol. The Co-Co coordination number extracted from the analysis of EXAFS data was found to increase to a value over 10 at $573 \mathrm{~K}$ (Table S4) despite the fact that only 6 is expected for a pure spinel structure, while 12 should be obtained for the $\mathrm{CoO}$ structure. The coordination number of $\mathrm{Co}-\mathrm{Fe}$ decreases correspondingly from 5.1 in the pristine $\mathrm{CoFe}_{2} \mathrm{O}_{4}$ sample to 3.9 during 2-propanol dehydrogenation at $573 \mathrm{~K}$.

Much more subtle changes are observed in the chemical state and coordination of Fe. The XANES spectra show a slight shift of the white line from 7133 in the as-prepared state to $7132.5 \mathrm{eV}$ at $573 \mathrm{~K}$ accompanied by a minor drop of the intensity (Figure 9a). The 
corresponding EXAFS spectra (Figure 9b) maintain their shape and positions of the main features with the overall magnitude decreasing as the reaction temperature increases. The main change can be observed in the decreasing EXAFS shoulder at $3.4 \AA^{-1}$ (uncorrected) that represents Fe-Co backscattering of octahedrally coordinated Fe. More detailed EXAFS analysis is not feasible with the data at hand as $\mathrm{Fe}$ in the spinel $\mathrm{CoFe}_{2} \mathrm{O}_{4}$ occupies sites in both octahedral and tetrahedral coordination.

Overall, the XAS spectra of the as-prepared $\mathrm{CoFe}_{2} \mathrm{O}_{4}$ NPs show a very close resemblance to the inverse spinel structure with octahedrally coordinated $\mathrm{Co}^{2+}$ ions and $\mathrm{Fe}^{3+}$ ions occupying both octahedral and tetrahedral sites (see SI for a detailed analysis). Some minor impurities, however, cannot be ruled out completely as indicated by Co-O coordination numbers $(\mathrm{CN})$ lower than 4, which is expected for tetrahedral sites (Table S4). Under reaction conditions the $\mathrm{CoO}$ structure evolves as indicated by a shift in the expansion of the Co-O bond, an increase of the Co-Co coordination number and a decrease of the Co-Fe coordination numbers. On the other hand, the chemical state of Fe, seem to be more stable under 2-propanol dehydrogenation conditions as the corresponding spectra change only due to a temperature-dependent increasing dynamic disorder and decreasing Fe-Co signal.

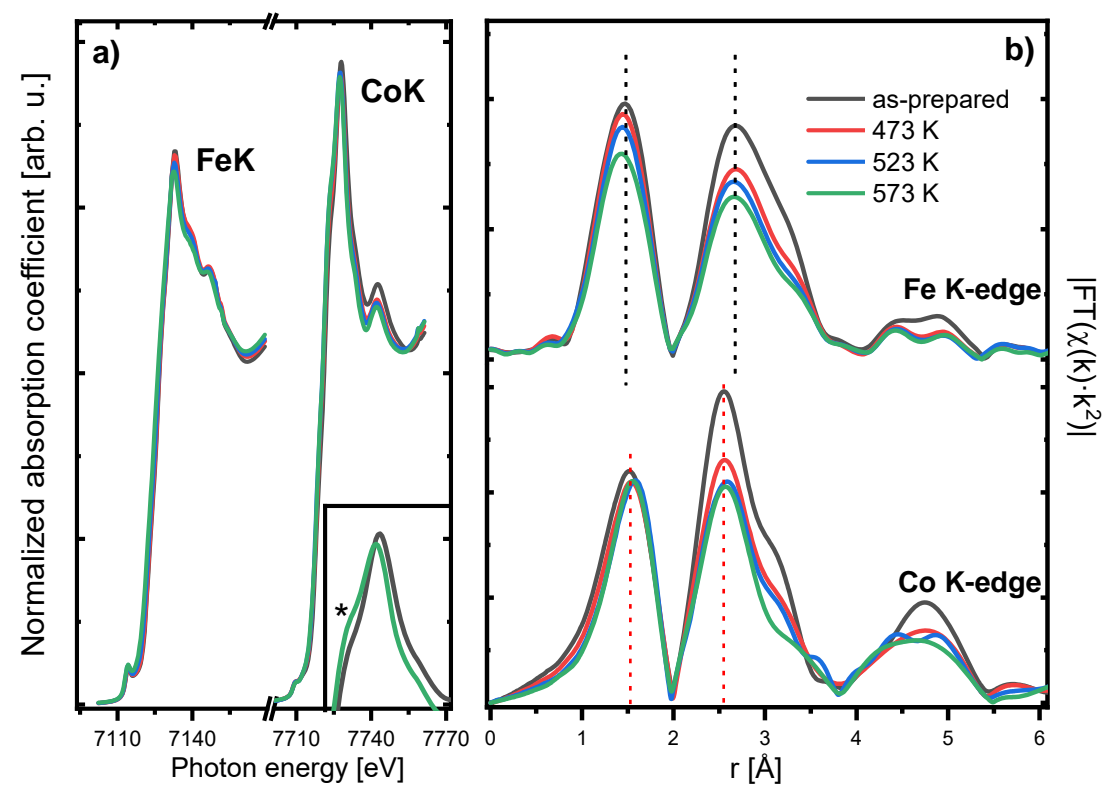


Figure 9. Co K-edge and Fe K-edge (a) XANES and (b) and EXAFS spectra of $\mathrm{CoFe}_{2} \mathrm{O}_{4} \mathrm{NPs}$ measured as-prepared and under 2-propanol dehydrogenation conditions. The inset in (a) shows the white-line regions of the Co K-edge XANES of the $\mathrm{CoFe}_{2} \mathrm{O}_{4}$ sample as-prepared and under 2-propanol dehydrogenation conditions at $573 \mathrm{~K}$. Black vertical lines in b mark the apparent positions for Fe-O and Fe-Fe scattering events in the as-prepared Fe K-edge EXAFS, red lines those for the for Co K-edge EXAFS spectra.

\section{Discussion}

The selective oxidation of 2-propanol over $\mathrm{CoFe}_{2} \mathrm{O}_{4} \mathrm{NPs}$ was investigated by a variation of the oxidative pretreatment as a function of temperature. For the initial oxidation run after oxidative pretreatment at $573 \mathrm{~K}$, the catalyst was found to be both active and selective over the whole temperature range, catalyzing the oxidative dehydrogenation to acetone and $\mathrm{H}_{2} \mathrm{O}$. At higher temperatures total oxidation yielding $\mathrm{CO}_{2}$ and $\mathrm{H}_{2} \mathrm{O}$ was also observed to a minor extent. The concomitant deactivation of the low-temperature activity was found in the subsequent reaction runs when lowering the reaction temperature. The temperature variation of the pretreatment in $\mathrm{O}_{2}$ revealed three conversion maxima. The low-temperature maximum at $430 \mathrm{~K}$ was observed after pretreatment at temperatures $\geq 523 \mathrm{~K}$, whereas an intermediate maximum in the 2-propanol conversion at $510 \mathrm{~K}$ was already found after pretreatment temperatures $\geq 473 \mathrm{~K}$, and the high-temperature activity was stable even after deactivation. Nevertheless, the selectivity at high temperatures depends on the pretreatment temperature. Acetone and $\mathrm{CO}_{2}$ yields were found to increase with increasing pretreatment temperature, while the propene yield simultaneously was found to decrease, indicating an increased selectivity towards 2-propanol dehydration for the deactivated catalyst. The same trend was observed for 2-propanol oxidation after $\mathrm{N}_{2} \mathrm{O}$ pretreatment. However, the pretreatment temperatures were $50 \mathrm{~K}$ higher than those employed for the $\mathrm{O}_{2}$ pretreatment used in the regeneration of the $\mathrm{CoFe}_{2} \mathrm{O}_{4} \mathrm{NPs}$ so that temperatures $\geq 573 \mathrm{~K}$ had to be applied for the $\mathrm{N}_{2} \mathrm{O}$ pretreatment.

The influence of reactive surface oxygen species on the low-temperature reaction pathway was investigated by $\mathrm{O}_{2}$ TPD experiments after the $\mathrm{O}_{2}$ and $\mathrm{N}_{2} \mathrm{O}$ pretreatment. The 
corresponding TPD profiles revealed the presence of atomic oxygen and surface lattice oxygen species and excluded the presence of molecular oxygen species on the catalyst surface independent of the oxidative atmosphere. Due to the high yields of the selectively formed oxidation product acetone and the low selectivity toward total oxidation, the reactive oxygen species involved during 2-propanol oxidation is identified to show nucleophilic character, most likely $\mathrm{O}^{2-}$ at the outermost surface. The higher amount of desorbing $\mathrm{O}_{2}$ after the $\mathrm{N}_{2} \mathrm{O}$ pretreatment indicates the ability of generating reactive atomic surface oxygen species on spinel surfaces by $\mathrm{N}_{2} \mathrm{O}$ decomposition.[17] Nevertheless, no correlation between the desorbing amount or the surface oxygen species and the low-temperature activity of the catalyst was found, which can explain the observed $50 \mathrm{~K}$ deviation between both pretreatments.

However, the choice of the oxidizing gas influenced the TPO profile. The consumption of the oxidizing gases coincides with the detection of $\mathrm{CO}_{2}$ and $\mathrm{H}_{2} \mathrm{O}$, indicating the oxidation of carbon- and hydrogen-containing residues on the catalyst surface. The amount of desorbing $\mathrm{CO}_{2}$ increased with increasing pretreatment temperature and correlated with the regeneration of the low-temperature pathway. After $\mathrm{O}_{2}$ pretreatment $\leq 423 \mathrm{~K}$, low-temperature activity was not observed, and the amounts of desorbing $\mathrm{CO}_{2}$ were low $\left(9-23 \mu \mathrm{mol} \mathrm{g} \mathrm{gat}^{-1}\right)$. After pretreatment at $473 \mathrm{~K}$, already $258 \mu \mathrm{mol} \mathrm{g}_{\mathrm{cat}}{ }^{-1} \mathrm{CO}_{2}$ had desorbed, and the intermediate conversion maximum is observed. After pretreatments at temperatures $\geq 523 \mathrm{~K}$, the $\mathrm{CO}_{2}$ amount is even 7 times larger and the low-temperature pathway was completely recovered. The slightly lower amount of $\mathrm{CO}_{2}$ observed for $623 \mathrm{~K}$ can be explained by accumulation of carbon-containing species due to incomplete oxidation in the previously performed TPOs. The correlation of the desorbing amount of $\mathrm{CO}_{2}$ and the occurrence of the low-temperature reaction pathway was also observed for the pretreatments in $\mathrm{N}_{2} \mathrm{O}$ and $\mathrm{He}$. The formation of $\mathrm{CO}_{2}$ during the inert pretreatment can occur due to decomposition of carbonates or oxidation of adsorbates by mobile oxygen species from the catalyst. The desorption of reactants and products during the inert pretreatment and the inhibition experiments with preadsorbed $\mathrm{CO}_{2}$ and acetone show no strong inhibiting effect on the active site. However, adsorption of acetic acid prior to the 2-propanol oxidation selectively 
inhibited the low-temperature pathway, while the intermediate and high-temperature maxima were not affected indicating a strong adsorption of acetate species on the active site for the lowtemperature oxidative dehydrogenation.

The formation of acetates and the inhibition of 2-propanol dehydrogenation was verified by performing in situ DRIFTS experiments. Upon interaction of 2-propanol and the $\mathrm{CoFe}_{2} \mathrm{O}_{4}$ NPs at ambient temperature only 2-propanol adsorption as 2-propoxide was observed. Additional bands for other surface species or gas-phase products were only detected at $503 \mathrm{~K}$. Formation of acetone and carbonates was observed, indicating conversion of 2-propanol. However, the corresponding bands disappear during desorption at high temperatures, verifying that acetone as well as carbonates are not inhibiting species for the $\mathrm{CoFe}_{2} \mathrm{O}_{4} \mathrm{NPs}$. Lukashuk et a1.[9] also described stable carbonates as spectator species, which play a minor role in CO oxidation over $\mathrm{Co}_{3} \mathrm{O}_{4}$. Only two bands assigned to acetate species remained, indicating its strong adsorption and inhibition of the catalytic activity. Acetate and carbonate species were also detected as important intermediates for the anaerobic ethanol decomposition by Vozniuk et al.[8,10] as well as during FTIR investigations of the oxidation of C3-compounds such as 2propanol and propene by the Lorenzelli group[11,32-34], but not clearly identified in the context of deactivation. To clarify if acetates can be removed and the low-temperature reaction pathway can be regenerated, DRIFT spectra were acquired during the oxidative treatment at 573 $\mathrm{K}$. The bands of acetate species became negative and the parallel increase of $\mathrm{CO}_{2}$ and $\mathrm{H}_{2} \mathrm{O}$ bands indicated the oxidation of acetates and their removal from the surface of the catalyst. Finocchio et al.[33] also found that acetates are stable at $473 \mathrm{~K}$, but disappeared at $573 \mathrm{~K}$.

Nevertheless, acetates are not the only species which can cause deactivation. Considering the mass balance during pretreatment in $\mathrm{O}_{2}$ at $573 \mathrm{~K}$ with regard to the identified surface adsorbates, deposition of elemental carbon on the $\mathrm{CoFe}_{2} \mathrm{O}_{4} \mathrm{NPs}$ during 2-propanol oxidation can be postulated. Carbon formation on the $\mathrm{CoFe}_{2} \mathrm{O}_{4}$ surface was confirmed by analyzing the C 1s region of ex situ XPS data of the used catalyst and in situ 2-propanol oxidation measurements. In their reaction scheme of propane oxidation over $\mathrm{Co}_{3} \mathrm{O}_{4}$, Finocchio 
et al.[33] described the formation of formate species in addition to acetate species from the intermediate 2-propoxide. The formate species were less stable than acetates and their decomposition leads to the formation of $\mathrm{OH}$ groups and $\mathrm{CO}$. The latter can be converted according to the Boudouard reaction which favors the formation of carbon and $\mathrm{CO}_{2}$ at low temperature and is additionally catalyzed by Fe. Carbon deposits, like the acetate species, can be removed by oxidative treatment.

XPS was also used to study the oxidation state of Co of the $\mathrm{CoFe}_{2} \mathrm{O}_{4}$ NPs and its changes upon 2-propanol oxidation reaction. Since the exposed cobalt ions are assumed to be the active site for the oxidation reaction, their oxidation or reduction can cause activation or deactivation, respectively. The Co $2 \mathrm{p}$ spectra reveal the dominant $\mathrm{Co}^{2+}$ oxidation state before and after reaction. However, the detailed analysis indicates a minor reduction of the cobalt species with an enrichment of $\mathrm{Co}^{2+}$ on the surface after reaction, but does not influence the catalytic activity as much as the acetate species, inhibiting the low-temperature activity. XAS proved that the cobalt species are exclusively occupying octahedral sites in the as-prepared $\mathrm{CoFe}_{2} \mathrm{O}_{4}$ NPs. Although Fe coordination remains mainly unchanged, significant changes in the local environment of Co can be observed during 2-propanol dehydrogenation. In particular, $\mathrm{CoO}$ can be fitted to some extent in XANES already at $473 \mathrm{~K}$ that then remains stable at higher reaction temperatures. EXAFS fitting results also confirm this conclusion based on Co-O bond expansion, an increase of $\mathrm{Co}-\mathrm{Co}$ and decrease of $\mathrm{Co}-\mathrm{Fe}$ coordination numbers.

\section{Conclusions}

Inverse spinel $\mathrm{CoFe}_{2} \mathrm{O}_{4} \mathrm{NPs}$ synthesized by the decomposition of metal acetylacetonates are highly active in the selective oxidation of 2-propanol. The unsupported $\mathrm{CoFe}_{2} \mathrm{O}_{4} \mathrm{NPs}$ catalyze the oxidative dehydrogenation of 2-propanol to acetone as main product over the whole investigated temperature range up to $573 \mathrm{~K}$ with a slightly decreasing selectivity due to total oxidation at the highest temperature. The observed low-temperature reaction pathway at $430 \mathrm{~K}$ is inhibited after an initial oxidation reaction run but can be restored by oxidative treatment. Deactivation was identified to originate from strongly bound acetate species as confirmed by 
poisoning experiments with acetic acid and in situ DRIFT spectroscopy. Also, the formation of carbon contributes to the decreased activity whereas carbonates are rather spectator species. The influence of reactive surface oxygen species on the deactivation process was excluded by temperature-programmed methods, and only a minor influence of surface reduction was deduced by XPS and XAS.

\section{Acknowledgements}

This research was funded by the Deutsche Forschungsgemeinschaft (DFG, German Research Foundation) - Project numbers 388390466 and 405034883 within the collaborative research centre/transregio TRR 247 "Heterogeneous Oxidation Catalysis in the Liquid Phase". The DFG core facility ICAN are gratefully acknowledged for performing the TEM characterization. Authors thank Lukas Pielsticker (RUB) as well as beamline staff at ALBA synchrotron, in particular, Dr. Carlo Marini and Dr. Nitya Ramanan, for their help during XAFS measurements. Funding from the European Research Council under grant ERCOPERANDOCAT (ERC-725915) is also appreciated. We acknowledge the Helmholtz-Zentrum Berlin for synchrotron radiation beamtime at ISISS beamline of BESSY II.

\section{Supplementary material}

Supplementary data to this article can be found online at https://doi.org/

\section{References}

[1] X. Xie, Y. Li, Z.-Q. Liu, M. Haruta, W. Shen, Low-temperature oxidation of CO catalysed by $\mathrm{Co}_{3} \mathrm{O}_{4}$ nanorods, Nature 458 (2009) 746-749.

[2] S. Zafeiratos, T. Dintzer, D. Teschner, R. Blume, M. Hävecker, A. Knop-Gericke, R. Schlögl, Methanol oxidation over model cobalt catalysts, J. Catal. 269 (2010) 309-317.

[3] D. Gu, C.-J. Jia, C. Weidenthaler, H.-J. Bongard, B. Spliethoff, W. Schmidt, F. Schüth, Highly Ordered Mesoporous Cobalt-Containing Oxides, J. Am. Chem. Soc. 137 (2015) 11407-11418.

[4] S. Jauhar, J. Kaur, A. Goyal, S. Singhal, Tuning the properties of cobalt ferrite, RSC Adv. 6 (2016) 97694-97719.

[5] K.F. Ortega, S. Anke, S. Salamon, F. Özcan, J. Heese, C. Andronescu, J. Landers, H. Wende, W. Schuhmann, M. Muhler, T. Lunkenbein, M. Behrens, Topotactic Synthesis of Porous Cobalt Ferrite Platelets from a Layered Double Hydroxide Precursor and Their Application in Oxidation Catalysis, Chem. Eur. J. 23 (2017) 12443-12449. 
[6] T. Baidya, T. Murayama, P. Bera, O.V. Safonova, P. Steiger, N.K. Katiyar, K. Biswas, M. Haruta, Low-Temperature CO Oxidation over Combustion Made Fe- and Cr-Doped $\mathrm{Co}_{3} \mathrm{O}_{4}$ Catalysts, J. Phys. Chem. C 121 (2017) 15256-15265.

[7] S. Anke, G. Bendt, I. Sinev, H. Hajiyani, H. Antoni, I. Zegkinoglou, H. Jeon, R. Pentcheva, B. Roldan Cuenya, S. Schulz, M. Muhler, Selective 2-Propanol Oxidation over Unsupported Co3O4 Spinel Nanoparticles, ACS Catal. 9 (2019) 5974-5985.

[8] O. Vozniuk, C. Bazzo, S. Albonetti, N. Tanchoux, F. Bosselet, J.-M.M. Millet, F. Di Renzo, F. Cavani, Structural Changes of Binary/Ternary Spinel Oxides During Ethanol Anaerobic Decomposition, ChemCatChem 9 (2017) 2219-2230.

[9] L. Lukashuk, N. Yigit, R. Rameshan, E. Kolar, D. Teschner, M. Hävecker, A. KnopGericke, R. Schlögl, K. Föttinger, G. Rupprechter, Operando Insights into CO Oxidation on Cobalt Oxide Catalysts by NAP-XPS, FTIR, and XRD, ACS Catal. 8 (2018) 86308641.

[10] O. Vozniuk, S. Agnoli, L. Artiglia, A. Vassoi, N. Tanchoux, F. Di Renzo, G. Granozzi, F. Cavani, Towards an improved process for hydrogen production, Green Chem. 18 (2016) $1038-1050$.

[11] G. Busca, M. Daturi, E. Finocchio, V. Lorenzelli, G. Ramis, R.J. Willey, Transition metal mixed oxides as combustion catalysts: preparation, characterization and activity mechanisms, Catal. Today 33 (1997) 239-249.

[12] K. Shojaee, A. Montoya, B.S. Haynes, Insight into oxygen stability and vacancy formation on $\mathrm{Co}_{3} \mathrm{O}_{4}$ model slabs, Comput. Mater. Sci. 72 (2013) 15-25.

[13] F. Zasada, W. Piskorz, J. Janas, E. Budiyanto, Z. Sojka, Dioxygen Activation Pathways over Cobalt Spinel Nanocubes - From Molecular Mechanism into Ab Initio Thermodynamics and ${ }^{16} \mathrm{O}_{2} /{ }^{18} \mathrm{O}_{2}$ Exchange Microkinetics, J. Phys. Chem. C 121 (2017) 24128-24143.

[14] Y. Takita, T. Tashiro, Y. Saito, F. Hori, The Effects of Water Coadsorption on the adsorption of Oxygen over Metal Oxides, J. Catal. 97 (1986) 25-35.

[15] G. Maniak, P. Stelmachowski, J.J. Stanek, A. Kotarba, Z. Sojka, Catalytic properties in $\mathrm{N}_{2} \mathrm{O}$ decomposition of mixed cobalt-iron spinels, Catal. Commun. 15 (2011) 127-131.

[16] P. Stelmachowski, G. Maniak, J. Kaczmarczyk, F. Zasada, W. Piskorz, A. Kotarba, Z. Sojka, $\mathrm{Mg}$ and $\mathrm{Al}$ substituted cobalt spinels as catalysts for low temperature $\mathrm{deN}_{2} \mathrm{O}$ Evidence for octahedral cobalt active sites, Appl. Catal., B 146 (2014) 105-111.

[17] J. Kaczmarczyk, F. Zasada, J. Janas, P. Indyka, W. Piskorz, A. Kotarba, Z. Sojka, Thermodynamic Stability, Redox Properties, and Reactivity of $\mathrm{Mn}_{3} \mathrm{O}_{4}, \mathrm{Fe}_{3} \mathrm{O}_{4}$, and $\mathrm{Co}_{3} \mathrm{O}_{4}$ Model Catalysts for $\mathrm{N}_{2} \mathrm{O}$ Decomposition, ACS Catal. 6 (2016) 1235-1246.

[18] L. Simonelli, C. Marini, W. Olszewski, M. vila Prez, N. Ramanan, G. Guilera, V. Cuartero, K. Klementiev, N.L. Saini, CLÆSS: The hard X-ray absorption beamline of the ALBA CELLS synchrotron, Cogent Physics 3 (2016) 1231987.

[19] B. Ravel, M. Newville, ATHENA, ARTEMIS, HEPHAESTUS: data analysis for X-ray absorption spectroscopy using IFEFFIT, J. Synchrotron Radiat. 12 (2005) 537-541.

[20] A. Knop-Gericke, E. Kleimenov, M. Hävecker, R. Blume, D. Teschner, S. Zafeiratos, R. Schlögl, V.I. Bukhtiyarov, V.V. Kaichev, I.P. Prosvirin, A.I. Nizovskii, H. Bluhm, A. Barinov, P. Dudin, M. Kiskinova, X-Ray Photoelectron Spectroscopy for Investigation of Heterogeneous Catalytic Processes, Adv. Catal. 52 (2009) 213-272.

[21] Q. Gu, X. Fu, X. Wang, S. Chen, D.Y.C. Leung, X. Xie, Photocatalytic reforming of C3polyols for $\mathrm{H}_{2}$ production, Appl. Catal., B 106 (2011) 689-696.

[22] H. Miyata, K. Hata, T. Nakajima, Y. Kubokawa, Infrared Studies of the Oxidation of 2propanol on ZnO, Bull. Chem. Soc. Jpn. (1980) 2401-2402.

[23] F. Arsac, D. Bianchi, J.M. Chovelon, C. Ferronato, J.M. Herrmann, Experimental microkinetic approach of the photocatalytic oxidation of isopropyl alcohol on $\mathrm{TiO}_{2}$. Part 1 . 
Surface elementary steps involving gaseous and adsorbed $\mathrm{C}_{3} \mathrm{H}_{(\mathrm{x})} \mathrm{O}$ species, J. Phys. Chem. A 110 (2006) 4202-4212.

[24] G.S. Foo, F. Polo-Garzon, V. Fung, D.-e. Jiang, S.H. Overbury, Z. Wu, Acid-Base Reactivity of Perovskite Catalysts Probed via Conversion of 2-Propanol over Titanates and Zirconates, ACS Catal. 7 (2017) 4423-4434.

[25] M. El-Maazawi, A.N. Finken, A.B. Nair, V.H. Grassian, Adsorption and Photocatalytic Oxidation of Acetone on $\mathrm{TiO}_{2}$, J. Catal. 191 (2000) 138-146.

[26] N.E. Fouad, P. Thomasson, H. Knözinger, Surface reactions of acetone, acetylene and methylbutynol on a yttrium-modified magnesium oxide catalyst, Appl. Catal., A 196 (2000) 125-133.

[27] X. Wang, Y. Liu, T. Zhang, Y. Luo, Z. Lan, K. Zhang, J. Zuo, L. Jiang, R. Wang, Geometrical-Site-Dependent Catalytic Activity of Ordered Mesoporous Co-Based Spinel for Benzene Oxidation, ACS Catal. 7 (2017) 1626-1636.

[28] J. Yang, H. Liu, W.N. Martens, R.L. Frost, Synthesis and Characterization of Cobalt Hydroxide, Cobalt Oxyhydroxide, and Cobalt Oxide Nanodiscs, J. Phys. Chem. C 114 (2010) 111-119.

[29] M.C. Biesinger, B.P. Payne, A.P. Grosvenor, L.W.M. Lau, A.R. Gerson, R.S.C. Smart, Resolving surface chemical states in XPS analysis of first row transition metals, oxides and hydroxides, Appl. Surf. Sci. 257 (2011) 2717-2730.

[30] T. Mathew, $\mathrm{Cu}-\mathrm{Co}$ Synergism in $\mathrm{Cu}_{1-\mathrm{x}} \mathrm{Co}_{\mathrm{x}} \mathrm{Fe}_{2} \mathrm{O}_{4}$ - Catalysis and XPS Aspects, J. Catal. 210 (2002) 405-417.

[31] P.N. Anantharamaiah, P.A. Joy, Enhancing the strain sensitivity of $\mathrm{CoFe}_{2} \mathrm{O}_{4}$ at low magnetic fields without affecting the magnetostriction coefficient by substitution of small amounts of Mg for Fe, Phys. Chem. Chem. Phys. 18 (2016) 10516-10527.

[32] G. Busca, E. Finocchio, V. Lorenzelli, G. Ramis, M. Baldi, IR studies on the activation of C-H hydrocarbon bonds on oxidation catalysts, Catal. Today (1999) 453-465.

[33] E. Finocchio, G. Busca, V. Lorenzelli, V.S. Escribano, FTIR studies on the selective oxidation and combustion of light hydrocarbons at metal oxide surfaces, J. Chem. Soc., Faraday Trans. 92 (1996) 1587-1593.

[34] E. Finocchio, R.J. Willey, G. Busca, V. Lorenzelli, FTIR studies on the selective oxidation and combustion of light hydrocarbons at metal oxide surfaces, J. Chem. Soc., Faraday Trans. 93 (1997) 175-180. 